\title{
13 UrEDAS, the Earthquake Warning System: Today and Tomorrow
}

\author{
Yutaka Nakamura, Jun Saita \\ System and Data Research Co. Ltd.
}

\section{Abstract}

The most important countermeasure against earthquake risk is to have all structures vulnerable enough for the possible earthquake load. In this regard, an early warning system should be installed to reduce the possibility of earthquake disaster. An early warning system is required mainly to issue an alarm to have a time margin for evacuating or shutting down key facilities, and not to determine exact earthquake parameters. Thus the early warning system must be realized independently and the government and other public authorities must release accurate earthquake information immediately.

The necessary qualities for early warning systems may be summarized as follows:

- Fully Automated: As the time margin is limited, the facility should be directly controlled without human judgment.

- Quick and Reliable: As there is limited time to respond to earthquake motion, this kind of system is required to be quick and reliable.

- Small and Cheap: To install easily, the system must be small and cheap.

- Independence: To issue fail-safe alarms, the system must be independent of other systems.

- Easy to Connect Network: To deliver the earthquake information, the system must be easy to connect network.

- Accuracy is Better: For the alarm, accuracy of the information is not such a serious problem.

UrEDAS, Urgent Earthquake Detection and Alarm System, is the first real-time P-wave alarm system in practical use in the world. It is able to process digitized waveforms step by step without storing the waveform data. As the amount of processing does not differ whether or not an earthquake occurs, system failure due to overload will not occur.

Here, the present condition of the P-wave early detection system UrEDAS is viewed under working conditions and the results of test observa- 
tions where faults exist are also reported. Then a new real-time data processing system for new generation will be considered.

\subsection{Introduction}

The most important countermeasure against earthquake risk is to have all structures vulnerable enough for the possible earthquake load. In this regard, an early warning system should be installed to reduce the possibility of earthquake disaster. An early warning system is required mainly to issue an alarm to have a time margin for evacuating or shutting down key facilities, and not to determine exact earthquake parameters. Thus the early warning system must be realized independently and the government and other public authorities must release accurate earthquake information immediately.

It is considered that an early warning system should have the following functions:

1. Rapid earthquake detection. Installing seismometers far from the target (e.g. urban area) is the easiest way to create enough time to escape. The time is caused by the difference in velocity between telecommunications $(300,000 \mathrm{~km} / \mathrm{sec})$ and the seismic wave $(8 \mathrm{~km} / \mathrm{sec})$. This type of early warning is called a "Front-detection system". Moreover if the system can detect $\mathrm{P}$ waves and determine the earthquake parameters or estimate the dangerousness of the earthquake motion, the time margin will be greater. In the event of P-wave detection, even near the target the warning system can obtain a time margin based on the difference between the $\mathrm{P}$ wave and $\mathrm{S}$ wave. This type of early warning system is called an "Onsite system".

2. Automatic management. All procedures for early warning and alarm must be carried out automatically, because human judgment may need time and can cause misjudgment.

3. Education and training in the system. It is necessary to educate the public with regard the meaning of the information or alarm from the early warning system. Also it is important to train staff how to behave in case of early warning and to promote manuals for the earthquake countermeasures.

4. That the possibility of false alarm and information error be recognized. Since there is always a possibility of issuing a false alarm, organizations that use the alarm system should understand taking risk. Obviously, attempts should be made to reduce the possibility of false alarms.

UrEDAS, Urgent Earthquake Detection and Alarm System, is the first real-time P-wave alarm system in practical use in the world. It is able to process digitized waveforms step by step without storing the waveform 
data. As the amount of processing does not differ whether or not an earthquake occurs, system failure due to overload will not occur.

Here, the present condition of the P-wave early detection system UrEDAS is viewed under working conditions and the results of test observations where faults exist are also reported. Then a new real-time data processing system for new generation will be considered. Table 13.1 shows the practice of early warning systems.

Table 13.1 Practice of early warning systems.

\begin{tabular}{|c|c|c|}
\hline & P-wave Alarm & S-wave Alarm \\
\hline $\begin{array}{l}\text { On-Site } \\
\text { Detection/Alarm }\end{array}$ & $\begin{array}{l}\text { Shinkansen lines since } \\
1998 \text { and Tokyo Metro since } \\
2001 \text { using Compact UrE- } \\
\text { DAS with One Second } \\
\text { Alarm after P-wave Detec- } \\
\text { tion }\end{array}$ & $\begin{array}{l}\text { Tokaido } \\
\text { Shinkansen since } \\
1964 \text { using Me- } \\
\text { chanical Detector }\end{array}$ \\
\hline \multirow{3}{*}{$\begin{array}{l}\text { Front } \\
\text { Detection/Alarm }\end{array}$} & $\begin{array}{l}\text { FREQL: } \\
\text { Sub-Seconds Alarm } \\
\text { after P-wave Detection } 2 \\
\text { as On-Site system for } \\
\text { Hyper Rescue Teams } \\
\text { since } 2005 \text { and for To- } \\
\text { kyo Metropolitan Subway } \\
\text { since } 2007\end{array}$ & $\begin{array}{l}\text { AcCo: more than } \\
200 \text { Users at the end } \\
\text { of 2005, mainly for } \\
\text { On-Site S-wave } \\
\text { Alarm }\end{array}$ \\
\hline & $\begin{array}{l}\text { One Second Alarm/ } \\
\text { Information after P-wave } \\
\text { Detection as Front sys- } \\
\text { tem for Nuclear Power } \\
\text { Plant since } 2006\end{array}$ & \\
\hline & $\begin{array}{l}\text { Tokaido } \\
\text { since 1992, } \\
\text { Shinkansen since 1996, for } \\
\text { Wakayama Tsunami Warn- } \\
\text { ing System since } 2001 \text { us- } \\
\text { ing UrEDAS with Three } \\
\text { Seconds Alarm/ Information } \\
\text { after P-wave Detection as } \\
\text { Front system }\end{array}$ & $\begin{array}{l}\text { Coast Line De- } \\
\text { tection System for } \\
\text { Tohoku Shinkan- } \\
\text { sen since } 1982 \\
\end{array}$ \\
\hline
\end{tabular}




\subsection{The History of Early Warning}

\subsubsection{The First Concept of Early Warning}

The main concept of the early warning system was introduced by Dr. Cooper in the San Francisco Daily Evening Bulletin of 3rd November 1868 (see Appendix). This report explained the concept as follows:

"A very simple mechanical contrivance can be arranged at various points from 10 to 100 miles from San Francisco, by which a wave of the earth high enough to do damage, will start an electric current over the wires now radiating from this city, and almost instantaneously ring an alarm bell, ... This bell should be very large, of peculiar sound, and known to everybody as the earthquake bell. Of course nothing but the distant undulation of the surface of the earth should ring it. This machinery would be self-acting and not dependent on the telegraph operators."

At that time, no system could realize this idea. Figure 13.1 shows the concept of Dr. Cooper's idea of the front detection system.

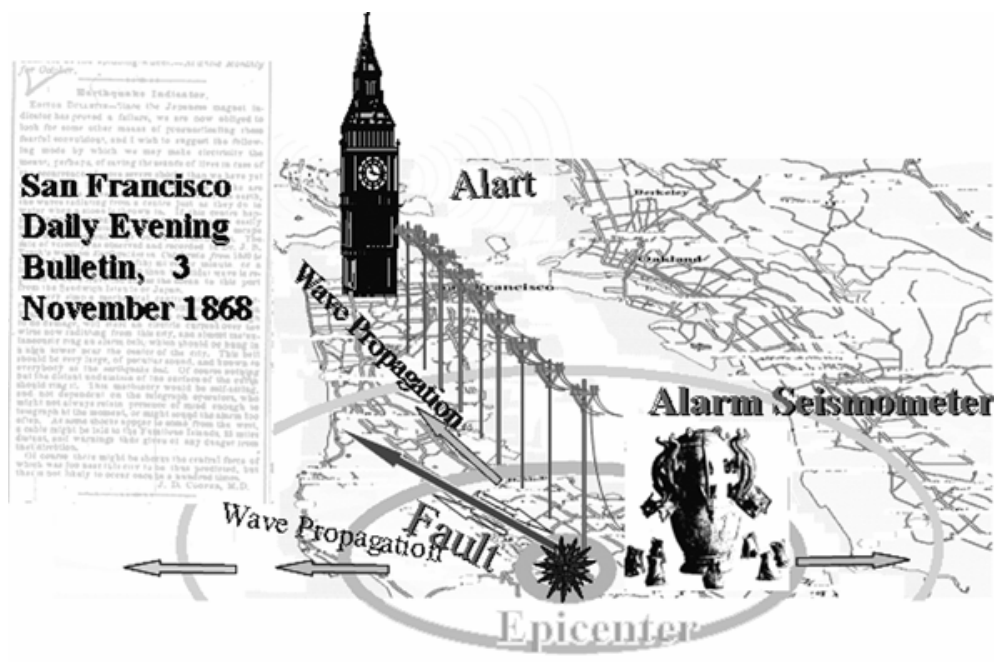

Fig. 13.1 The concept of the first detection system by Dr. Cooper.

\subsubsection{Earthquake Alarm for Railways}

Earthquake detectors for the railway system were developed and spread from the second half of 1950s in Japan. It was started by the strong motion 
observation with SMAC, the first strong-motion seismograph in Japan developed in 1953. The 1964 Niigata earthquake (M7.5) triggered debate on an earthquake warning system for Shinkansen under construction.

However, in April 1965, the year after starting operation of Tokaido Shinkansen (bullet train), an M6.1 earthquake occurred in Shizuoka prefecture and some structures in Shinkansen were damaged. Subsequently, JNR, Japanese National Railways, decided to construct a new earthquake warning system with ordinary alarm seismometers and waveform recording seismometers. These seismometers were installed every 20 to 25 $\mathrm{km}$ along the Shinkansen line to issue an alarm if the acceleration of horizontal ground motion exceeds $40 \mathrm{Gal}\left(=\mathrm{cm} / \mathrm{sec}^{2}\right)$. This preset level, 40 $\mathrm{Gal}$, was determined as a level to detect earthquakes exactly, so as not to issue alarms in the event of small earthquakes, and not to issue errors with passing trains or other environmental noise. Figure 13.2 shows the examples of these historical earthquake detectors.
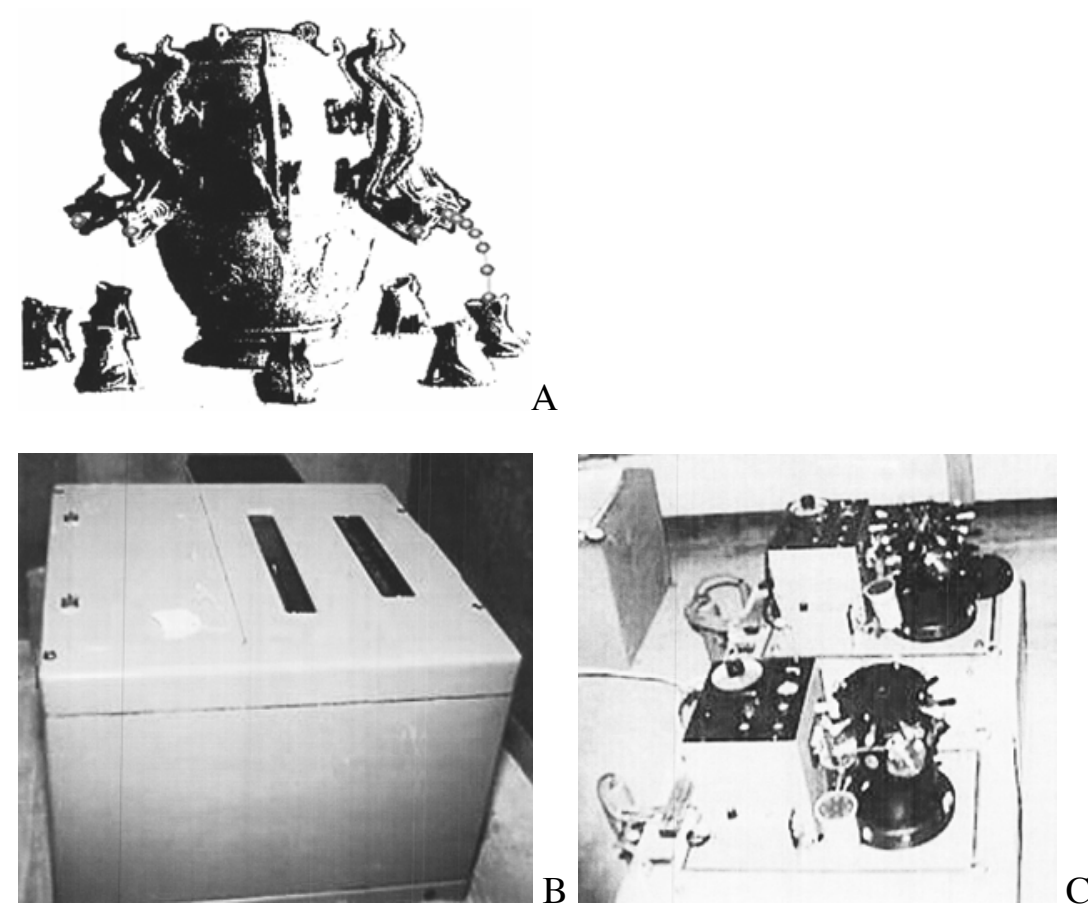

Fig. 13.2 Historical earthquake detectors. (A) The first earthquake detector in ancient China (model). (B) SMAC type strong motion detector (appearance). (C) Earthquake detector for Shinkansen (inside). 
In 1972, researchers in earthquake disaster prevention in Japan advocated the "Strong earthquake alarm system 10 seconds before". Although this was an idea similar to Dr. Cooper's front detection system in 1868, nobody had put it into practical use until then. The world's first front detection system, "a coastline detection system" with the simple triggering seismograph, began operations at the time of the completion of the Tohoku Shinkansen in 1982. This is the first example which carried through Dr. Cooper's idea into practice, followed by the Mexico-based SAS (Sistema de Alerta Sísmica) installed in 1991 similar to this coastline detection system. Figure 13.3 shows the coast line detection systems for the Tohoku Shinkansen line and so on.

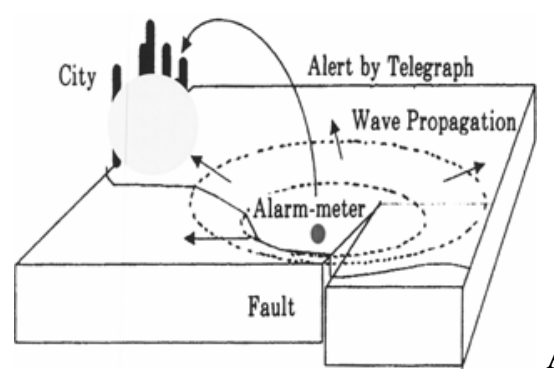

A
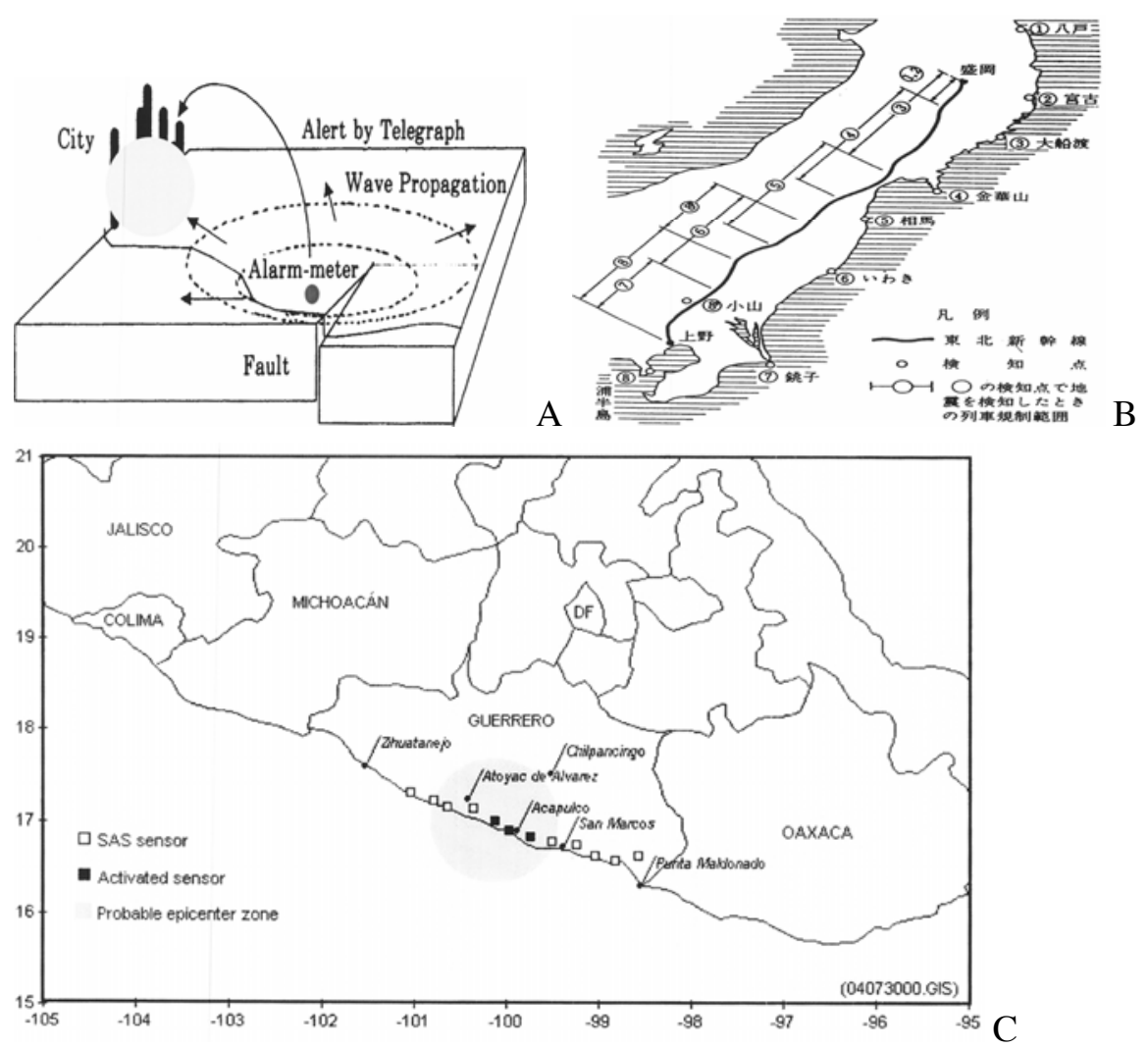

Fig. 13.3 Coastline detection systems. (A) Dr. Cooper's idea (1868). (B) Coastline detection system for Tohoku Shinkansen (1982). (C) SAS, Sistema de Alerta Sísmica, of Mexico (1991). 


\subsubsection{Birth of UrEDAS}

Since earthquake detection with a simple trigger is required to set the threshold level high, earthquake detection tends to be late after S-wave arrival. If it is possible to detect a $\mathrm{P}$ wave, the duration of the preliminary tremor can be used for countermeasures. If a front detection system with Pwave detection can be created, then the time margin may be expected to increase. Thus P-wave detection and an alarm system were developed as an indispensable system for a high-speed train. This system was completed as a UrEDAS which can estimate the earthquake parameters and issue an alarm in three seconds after P-wave detection. The prototype UrEDAS started observations in 1984. Since 1988, UrEDAS has been used in practice as part of an earthquake disaster prevention system for the Seikan undersea tunnel (see Fig. 13.4). For the Shinkansen lines, after trial operation started in 1990, UrEDAS started operating with 14 stations for the Tokaido Shinkansen line in 1992. This is the first front P-wave detection alarm system in practical use as an automatic train controlling system.

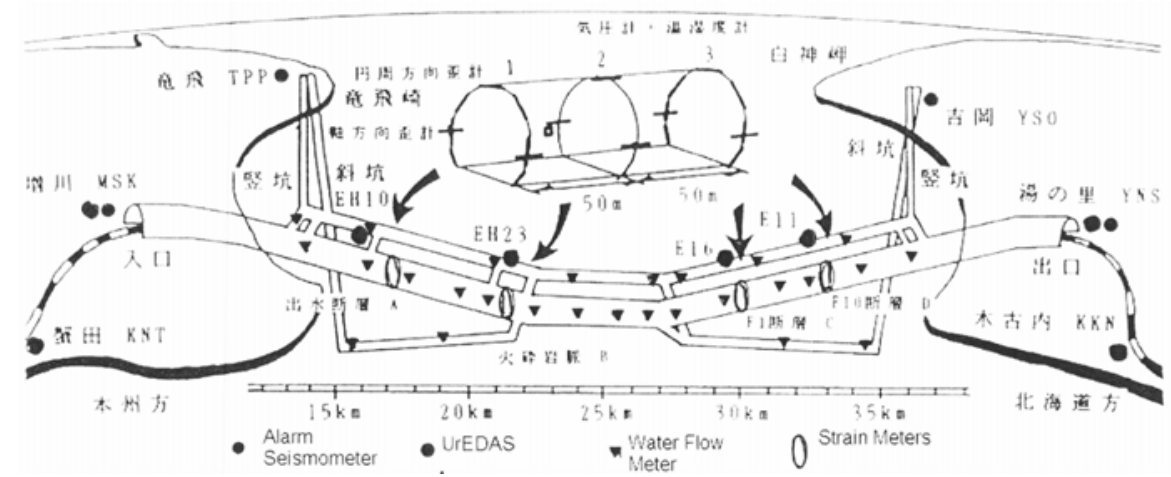

Fig. 13.4 Earthquake disaster detection system for Seikan undersea tunnel.

\subsubsection{After the Kobe earthquake}

The 1995 Kobe Earthquake (M7.2) caused extensive and severe damage to viaducts and other structures. This time along-the-railroad alarm seismometers issued the alarm immediately since the station was close to the epicenter. This earthquake led to a plan to install the Sanyo Shinkansen UrEDAS. The system was completed and operation was started with five stations in 1996. In 2000, a UrEDAS was installed in Kushimoto, the southern end of Honshu Main Island, as a tsunami warning system by Wakayama prefecture, and observations have continued since then. 
The Kobe Earthquake also provided the motivation for CompactUrEDAS development. In the VTR shown in Fig. 13.5, initial P-wave motion was detected as something happening, and then severe motion started. In an interview with victims, although there were only a few seconds between detection of something happening to earthquake recognition, there was anxiety and fear because they could not understand what was happening during this period and felt relieved after recognition of earthquake occurrence. To counter this kind of feeling, earlier earthquake alarm was required: Compact UrEDAS was developed to issue the alarm within one second of P-wave arrival.

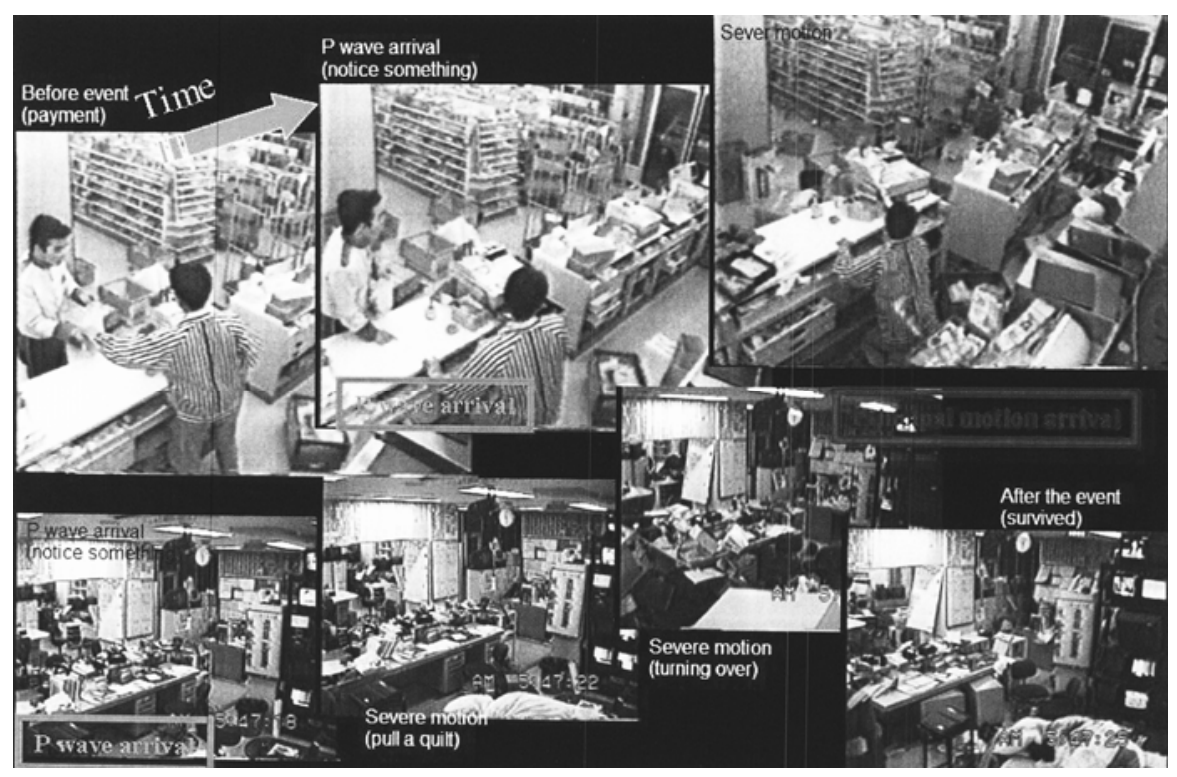

Fig. 13.5 VTR at the time of the Kobe earthquake.

After the Kobe earthquake, there was a plan to update and renew the alarm system for the Shinkansen lines of East Japan Railways in the northern part of Japan. A compact UrEDAS was chosen for this plan, which can issue the alarm immediately - at almost one second after P-wave detection - based on the dangerousness of the detected earthquake motion, and also issue the alarm with an $\mathrm{S}$ wave. 56 sets of Compact UrEDAS were installed for Shinkansen lines of East Japan Railways and started operation only with an S-wave alarm in 1997. After adjustment for the P-wave alarm, this system started full operations in 1998 as an along-the-railroad on-site P-wave detection system. 
For the subway network in the Tokyo metropolitan area, six sets of Compact UrEDAS were installed in 1998 and started operation immediately with only S-wave alarms. In 2001, this subway Compact UrEDAS was in practical use as an automatic train control system with a P-wave alarm system. This subway Compact UrEDAS was replaced to FREQL, the next generation of UrEDAS and Compact UrEDAS, in 2007.

Figure 13.6 shows the distribution map of the stations for UrEDAS and Compact UrEDAS after the Kobe earthquake.

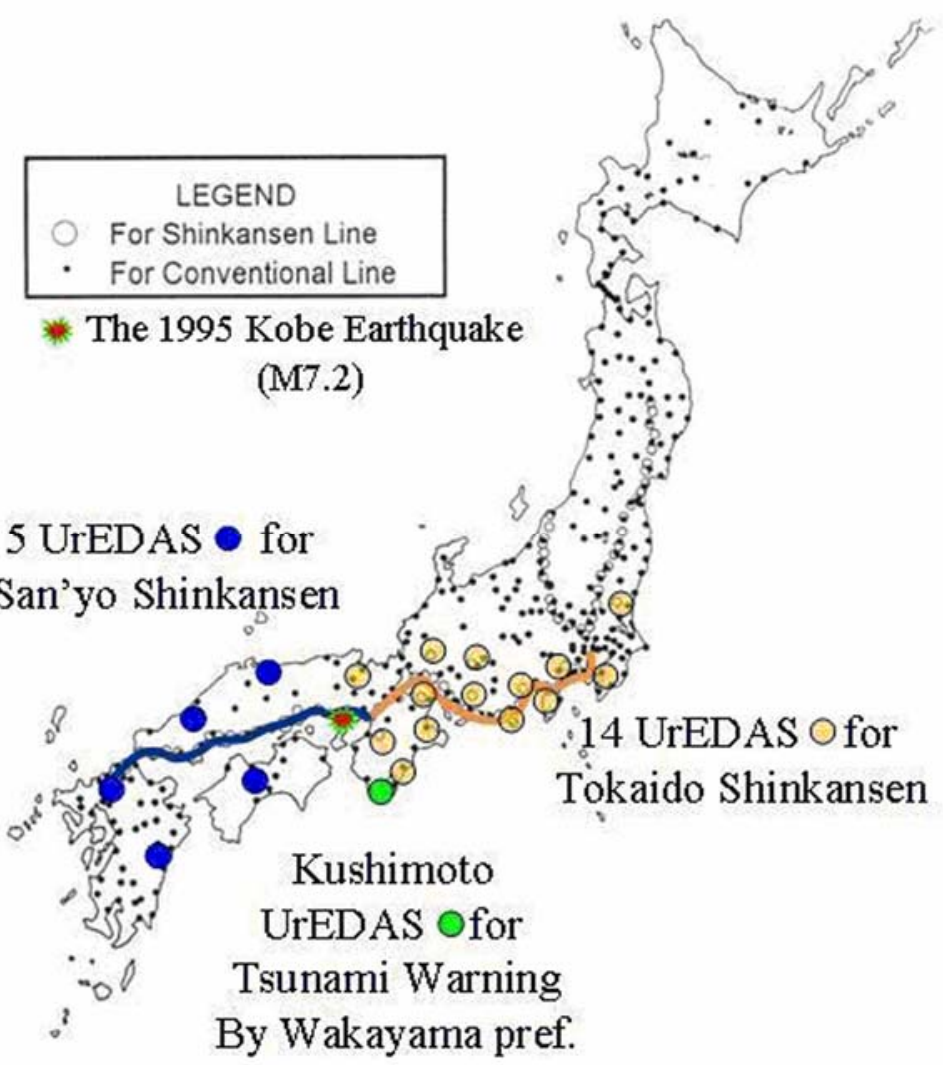

Fig. 13.6 Distribution of UrEDAS and Compact UrEDAS. 


\subsection{UrEDAS}

\subsubsection{UrEDAS Functions}

Main UrEDAS functions are estimation of magnitude and location, vulnerability assessment and warning within a few seconds of initial $\mathrm{P}$ wave motion at a single station. Unlike the existing automatic seismic observation systems, UrEDAS does not have to transmit the observed waveform in real time to a remote processing or centralized system and thus the system can be considerably simplified.

UrEDAS calculates parameters such as back azimuth, predominant frequency and vertical to horizontal ratio, using amplitude level for each sampling in real time. These calculations are basically processed in real time without storing waveform data. UrEDAS calculates these values continuously regardless of whether or not an earthquake occurs, and calculates just like filtering, so the number of procedures is not increased in the event of an earthquake. UrEDAS can detect earthquakes in P-wave triggering with the amplitude level, and then estimates earthquake parameters such as magnitude, epicentral and hypocentral distance, depth and back azimuth from the result of real-time calculation in a fixed period. Moreover UrEDAS can support restarting operation based on the detailed earthquake parameters.

\subsubsection{Estimation of Magnitude and Location}

(1) P-wave Recognition and Estimation of Azimuth Using Single Station Information

Figure 13.7 shows the methods for P-wave recognition and estimation of azimuth using single station information, seismic wave recognition and epicentral azimuth estimation using three components of the single station. If the vertical component is larger than the horizontal component, the wave will be a $\mathrm{P}$ wave. Figure 13.8 shows a comparison between the initial motion periods automatically read by the UrEDAS and the magnitudes given by JMA. The magnitude estimated by UrEDAS seems to be within almost \pm 0.5 of its JMA counterpart.

\section{(2) Magnitude}

The magnitude of an earthquake relates to the size of a seismic fault: the larger the fault, the greater the magnitude. Also the duration and the predominant period of the motion are proportional to earthquake magnitude. Therefore, the magnitude of an earthquake can be predicted from the predominant period of the initial motion as in Fig. 13.9. 


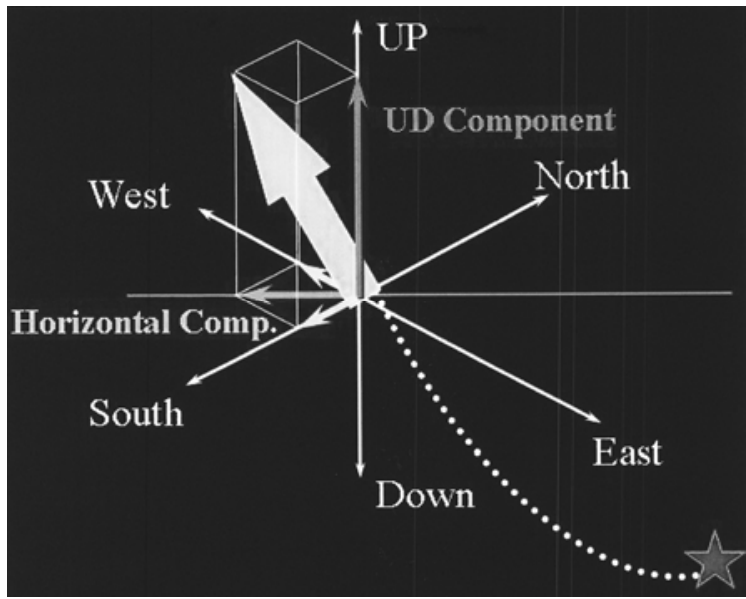

Fig. 13.7 Estimation of $\mathrm{P}$ wave recognition.

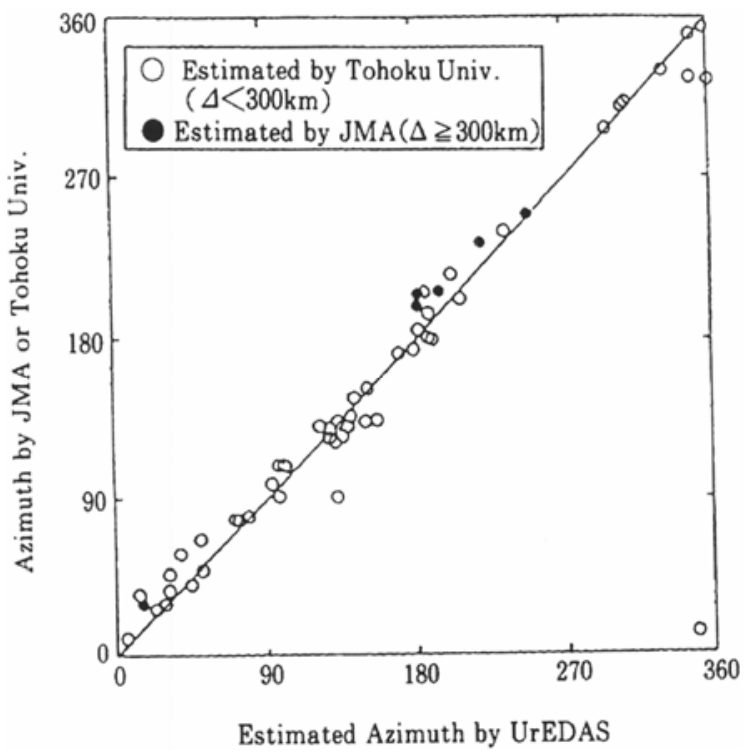

Fig. 13.8 Estimation of back azimuth. 


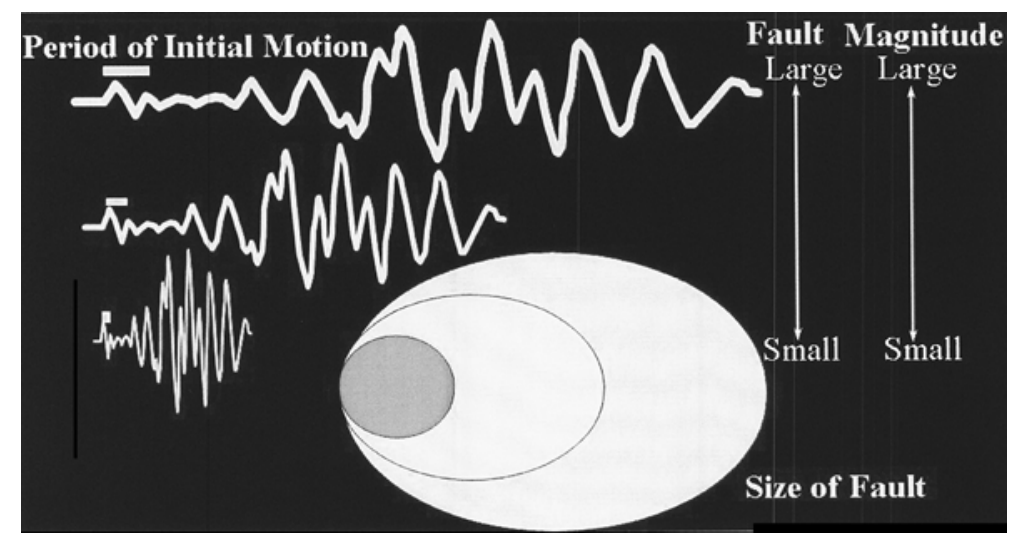

Fig. 13.9 Relationship between the period of initial motion and magnitude.

UrEDAS uses both acceleration and velocity of the earthquake motion for continuous estimation of the predominant frequency in real time. Amplitude level of the motion is calculated continuously with exponential smoothing and then the predominant frequency is estimated from the ratio of acceleration level to velocity level. This corresponds to the frequency of the gravity center of velocity spectrum. Figure 13.10 shows the change in the predominant frequency of actual earthquake motion, and shows it is possible to grasp the change of the predominant frequency.

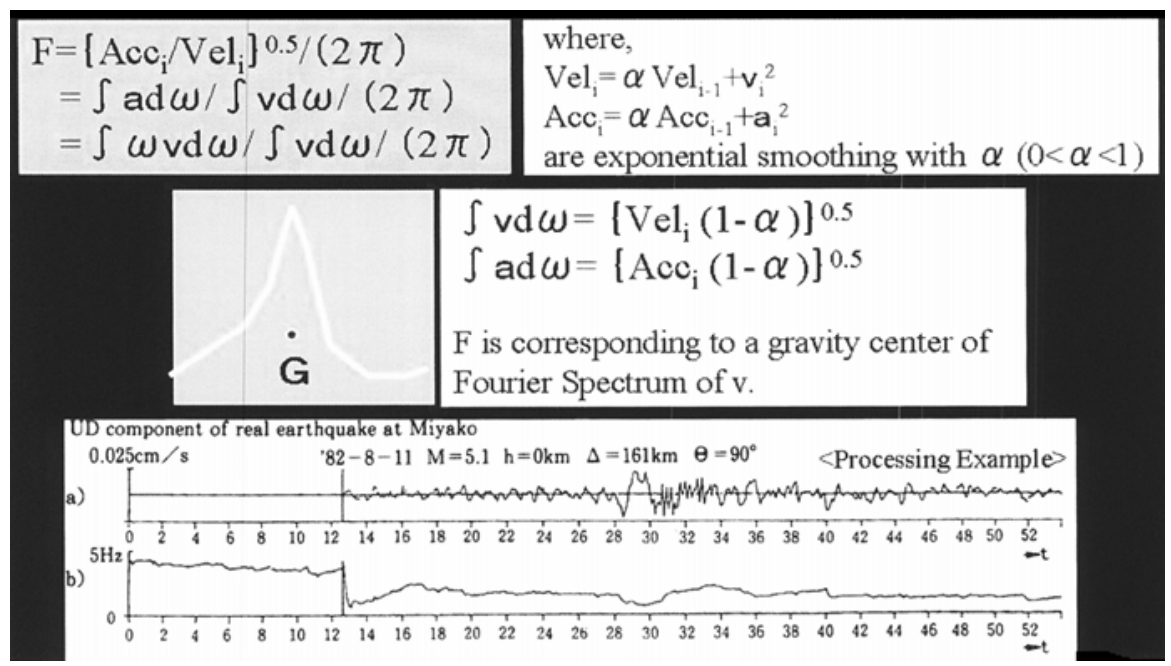

Fig. 13.10 Estimation of the predominant frequency. 
Figure 13.11 shows the performance of continuous estimation of the predominant frequency based on the proposed technique. The first example shows the result of inputting a sine curve with various amplitudes and frequencies. Amplitude does not affect the estimation result but the change in predominant frequency is immediately detected. In the case of real earthquake motion, since amplitude increases drastically with P-wave arrival, detection of the change in predominant frequency is extremely rapid.

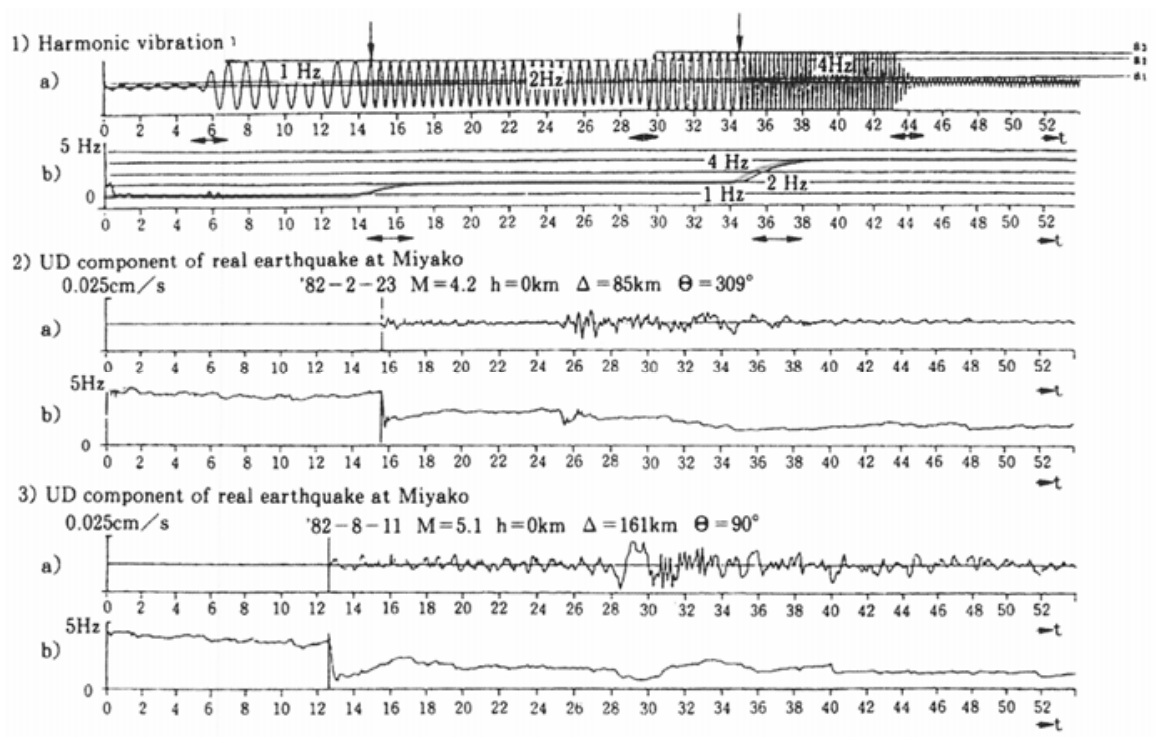

Fig. 13.11 Performance of continuous estimation of predominant frequency.

Figure 13.12 shows a comparison between the initial motion periods automatically read by the UrEDAS and the magnitudes given by JMA. The magnitude estimated by UrEDAS seems to be almost within \pm 0.5 that of JMA. Figure 13.13 shows the comparison between the official magnitude of JMA and the UrEDAS magnitude estimated in real time with the initial $P$ wave. Estimated magnitude is a little larger but the scatter is in \pm 1 . It is not a serious problem for the alarm system to estimate slightly large because of the view of the safety side.

Additionally magnitude of distant and deep earthquakes are estimated smaller but this constitutes no problem in terms of alarm, as in general deep earthquakes do not cause serious damage. 


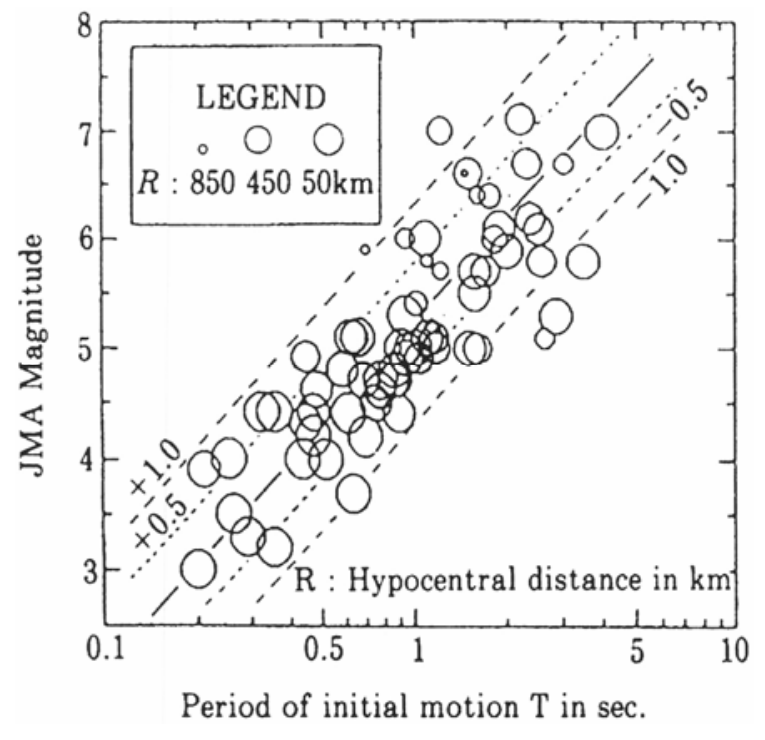

Fig. 13.12 Comparison between the period of the initial motion and magnitude.

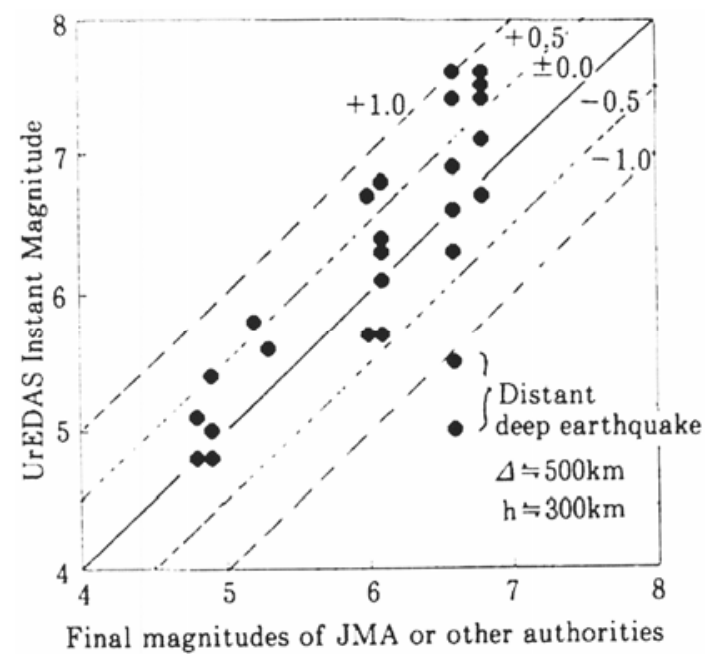

Fig. 13.13 Estimated magnitude and JMA magnitude. 


\section{(3) Epicentral Distance and Depth}

In general, the magnitude of an earthquake is predicted from the amplitude of the initial motion and the distance from the epicenter. As the amplitude of an initial motion can be automatically measured and the magnitude of the earthquake can be estimated from the period of the initial motion, the epicentral distance can be estimated from this information. The depth can be estimated statistically using a parameter, the ratio of the vertical initial motion to the horizontal initial motion as a kind of the angle of seismic wave incidence. Although the accuracy of estimating the epicentral distance in this way is not so high (half to twice the distance), more accurate estimation by using the duration of preliminary tremors is possible after the arrival of the principal motion.

\subsubsection{Vulnerability Assessment and Warning Based on M- $\Delta$ Relation}

Past earthquake damage for railway structures is plotted in this M- $\Delta$ diagram, with earthquake magnitude on the $\mathrm{x}$ axis and epicentral distance on the $y$ axis as in Fig. 13.14.

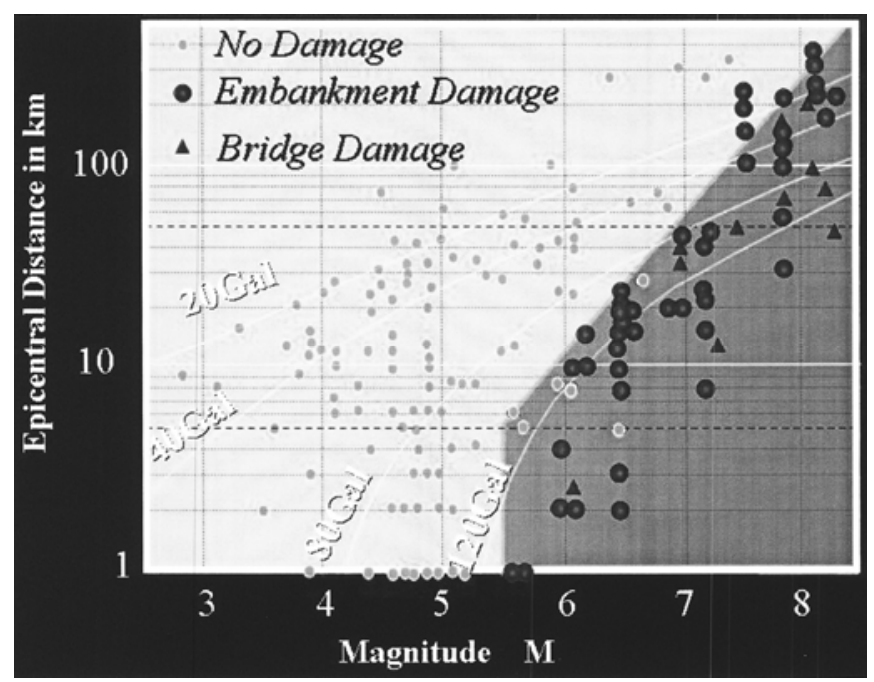

Fig. 13.14 M- $\Delta$ diagram

It clearly shows damage occurs for $\mathrm{M}>5.5$, and damaged areas are confined within a certain distance range around the epicenter. For example, 
earthquakes with M6, M7 and M8 give damage $12 \mathrm{~km}, 60 \mathrm{~km}$ and $300 \mathrm{~km}$ within epicentral distances, respectively. If we could rapidly estimate the earthquake magnitude and epicenter location with depth, the area to be alerted is clearly shown by the M- $\Delta$ diagram and a reasonable alarm can be issued immediately after earthquake detection. This new alarm is referred to as an M- $\Delta$ Alarm.

\subsection{Compact UrEDAS}

\subsubsection{Assessment Index for Vulnerability of Strong Motion}

Compact UrEDAS estimates the expected destructiveness of the earthquake immediately from the earthquake motion directly, not from the earthquake parameters as UrEDAS, and then issues the alarm if needed. To estimate earthquake dangerousness, the power of the earthquake motion is calculated from the inner product of acceleration vector and velocity vector, but this value will be large. Hence Destructive Intensity (DI) is defined as the logarithm of absolute value of this inner product as in Fig. 13.15.

Figure 13.16 shows the change in DI as a function of time. When the $\mathrm{P}$ wave arrives, DI increases drastically. PI value is defined as maximum DI within $\mathrm{t}$ seconds after P-wave detection. This value is suggested to be used for P-wave alarm. Subsequently, DI continues to increase slowly until the $\mathrm{S}$-wave arrival, after which it reaches its maximum value which is called the DI value. This value relates to earthquake damage and is similar to the Instrumental Intensity scale of JMA or Modified Mercalli Intensity (MMI).

Instrumental JMA seismic intensity can be determined only after the earthquake has terminated. On the other hand, DI has a very important practical advantage, because it can be calculated in real time soon after the $\mathrm{P}$-wave arrival with physical meaning. In other words, with the continuous observations of DI, an earthquake alarm can be issued efficiently and damage can be estimated precisely.

Figure 13.17 shows the relationship between the DI value, PI value and maximum acceleration. Common alarm seismometers are triggered $40 \mathrm{Gal}$ and $80 \mathrm{Gal}$ of acceleration. These trigger levels correspond to 2.0 and 2.5 of PI value, respectively. The actual Compact UrEDAS are set 2.5 to 3.0 of PI value. 


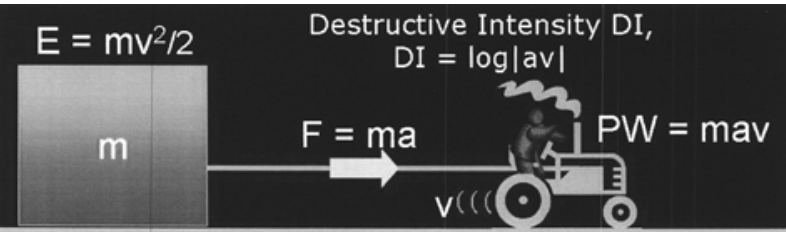

Fig. 13.15 Overview of Destructive Intensity, DI.

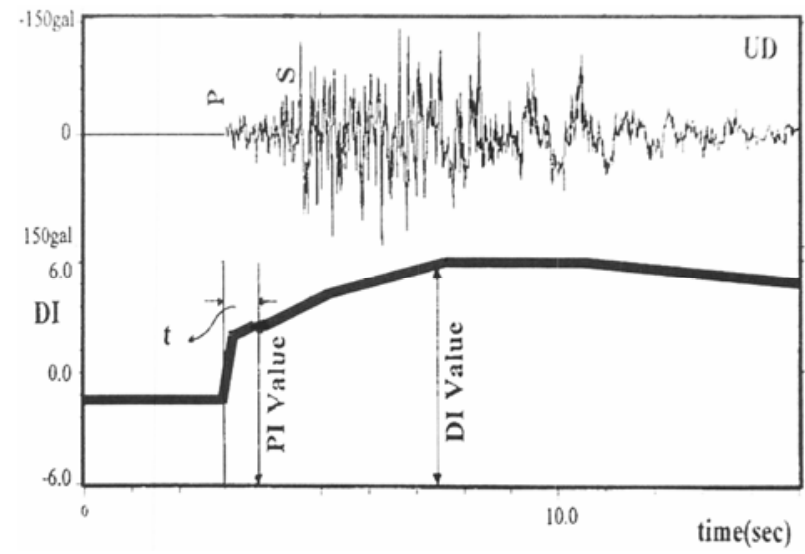

Fig. 13.16 Change of DI.

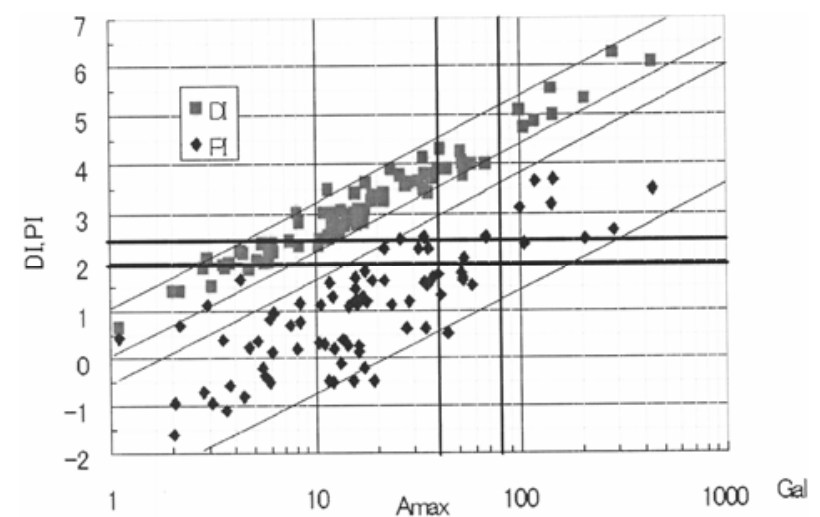

Fig. 13.17 Relationship between DI value, PI value and maximum acceleration. 


\subsubsection{Alarms of Compact UrEDAS Based on Destructive Intensity and Acceleration Level}

Figure 13.18 is a schematic diagram for alarms of Compact UrEDAS. Compact UrEDAS issues alarms not only on P-wave arrival but also Swave arrival. Thus Compact UrEDAS achieves both rapidity and reliability by combining $\mathrm{P}$-wave and $\mathrm{S}$-wave alarms.

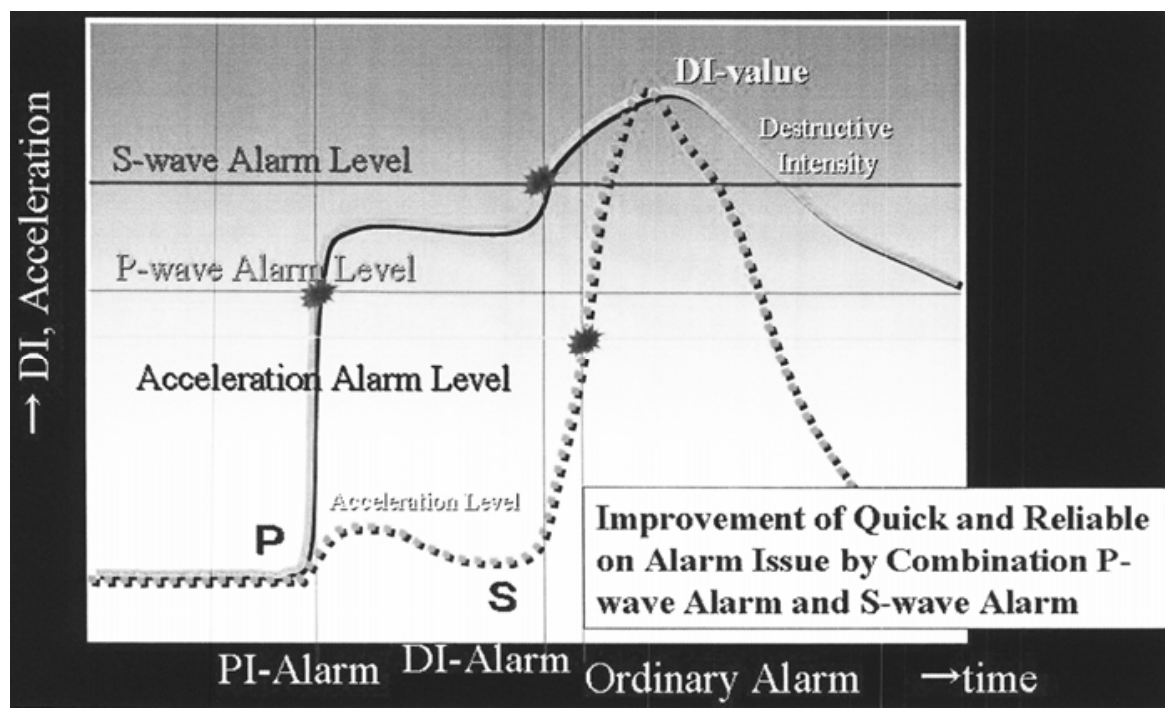

Fig. 13.18 Schematic diagram for Compact UrEDAS alarm.

\subsection{Operating Conditions}

\subsubsection{Overview of the Operating Conditions}

Table 13.2 shows the result of UrEDAS operations on Tokaido Shinkansen for approximately 14 years. Initially, the UrEDAS alarm threshold level was set at M4.5 for adjustment. As a result, the UrEDAS alarm was issued more than the ordinary alarm. But after adjustment, the number of UrEDAS alarms decreased, which shows the system has achieved a rational alarm. 
Table 13.2 An example of UrEDAS operation result.

\begin{tabular}{|c|c|c|c|c|c|c|}
\hline \multirow[b]{2}{*}{ Period } & \multirow[b]{2}{*}{$\begin{array}{l}\text { Total } \\
\text { Num. }\end{array}$} & \multicolumn{3}{|c|}{ UrEDAS Alarm } & \multirow[b]{2}{*}{$\begin{array}{l}\text { Common } \\
\text { Alarm }\end{array}$} & \multirow{2}{*}{$\begin{array}{c}\text { Ordinary } \\
\text { Alarm } \\
\text { (5HzPGA> } \\
40 \mathrm{Gal})\end{array}$} \\
\hline & & $M>5.5$ & $\mathrm{EN}^{* 1}$ & $\mathrm{DBE}^{2}$ & & \\
\hline $\begin{array}{c}3-12, \\
1992\end{array}$ & 11 & $7^{* 3}$ & 2 & 1 & 0 & 1 \\
\hline $\begin{array}{c}1-12 \\
1993\end{array}$ & 7 & 2 & 0 & 2 & 0 & 3 \\
\hline $\begin{array}{c}1-12 \\
1994\end{array}$ & 4 & 1 & 0 & 0 & 1 & 4 \\
\hline $\begin{array}{l}1-12, \\
1995\end{array}$ & 7 & 2 & 0 & 0 & $1^{* 4}$ & 6 \\
\hline $\begin{array}{c}1-12 \\
1996\end{array}$ & 3 & 0 & 0 & 0 & 0 & 3 \\
\hline $\begin{array}{l}1-12, \\
1997\end{array}$ & 5 & 1 & 0 & 0 & 1 & 5 \\
\hline $\begin{array}{l}1-12, \\
1998\end{array}$ & 2 & 1 & 0 & 0 & 0 & 1 \\
\hline $\begin{array}{l}1-12, \\
1999\end{array}$ & 1 & 0 & 0 & 0 & 0 & 1 \\
\hline $\begin{array}{c}1-12 \\
2000\end{array}$ & 5 & 2 & 0 & 1 & 0 & 2 \\
\hline $\begin{array}{c}1-12 \\
2001\end{array}$ & 4 & 0 & 0 & 0 & 0 & 4 \\
\hline $\begin{array}{c}1-12 \\
2002\end{array}$ & 0 & 0 & 0 & 0 & 0 & 0 \\
\hline $\begin{array}{c}1-12 \\
2003\end{array}$ & 1 & 0 & 0 & 0 & 0 & 1 \\
\hline $\begin{array}{c}1-12 \\
2004\end{array}$ & 2 & 2 & 0 & 0 & 2 & 2 \\
\hline $\begin{array}{c}1-12 \\
2005\end{array}$ & 2 & 1 & 0 & 0 & 1 & 2 \\
\hline EN: E & 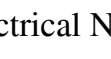 & & & & & \\
\hline $\begin{array}{l}* 2 \text { DBE: } \\
* 3 \text { M }>4.5\end{array}$ & tance $\mathrm{I}$ & Earthqua & & & & \\
\hline
\end{tabular}




\subsubsection{Practical Use}

\section{(1) The 1994 Northridge earthquake}

During the first 24 hours after the Northridge earthquake, UrEDAS detected about 700 aftershocks whose magnitude and hypocenter locations were automatically estimated as in Fig. 13.19.

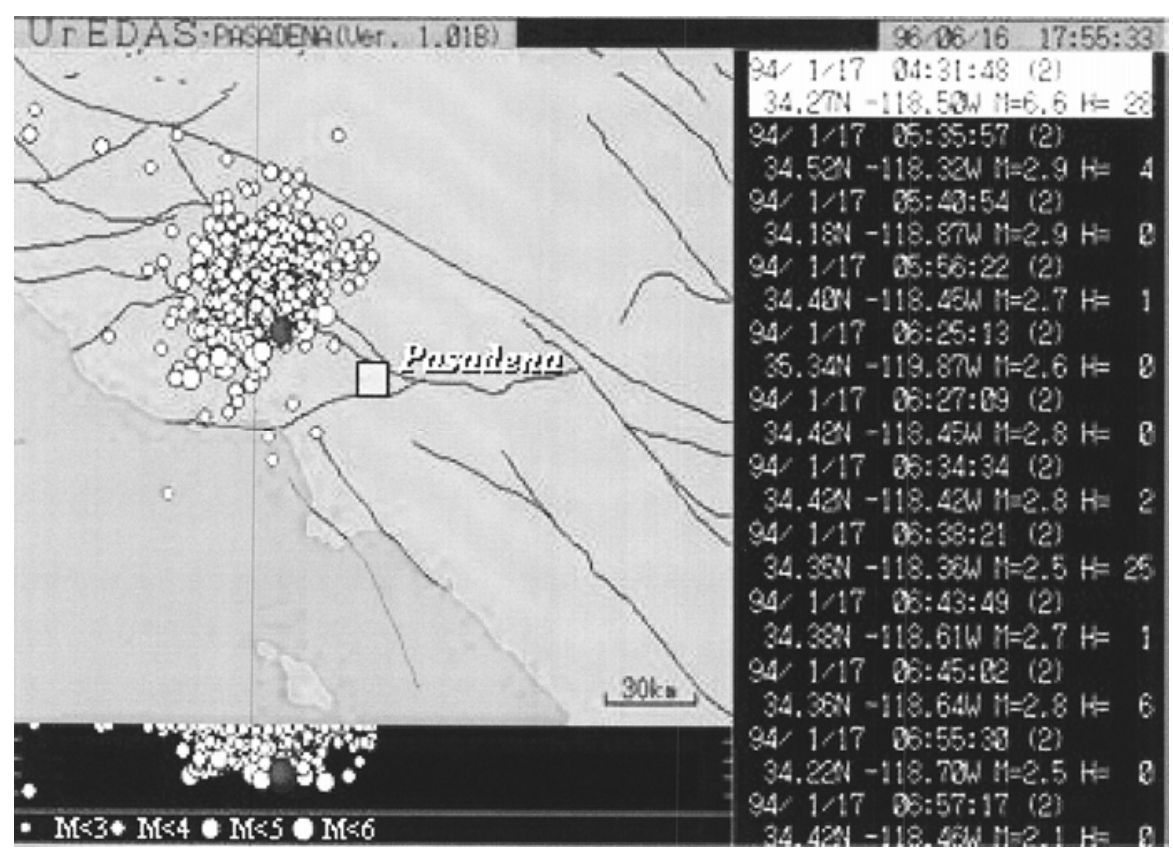

Fig. 13.19 The 1994 Northridge earthquake and after shocks observed by Caltech UrEDAS.

\section{(2) The 1995 Kobe earthquake}

Figure 13.20 shows the results of monitoring the Kobe Earthquake sequence during the two weeks after the main shock. Although these figures are based on the data from only one UrEDAS station, aftershock activity was almost correctly traced. At the time of the earthquake, an onsite alarm seismometer issued an alarm instantaneously due to the distance from the epicenter, but also UrEDAS issued an alarm at the same time or a little later. Unfortunately, the alarm did not arrive at the target area due to the transmission system failure. This is a typical example showing the difficulty of controlling the remote target. 


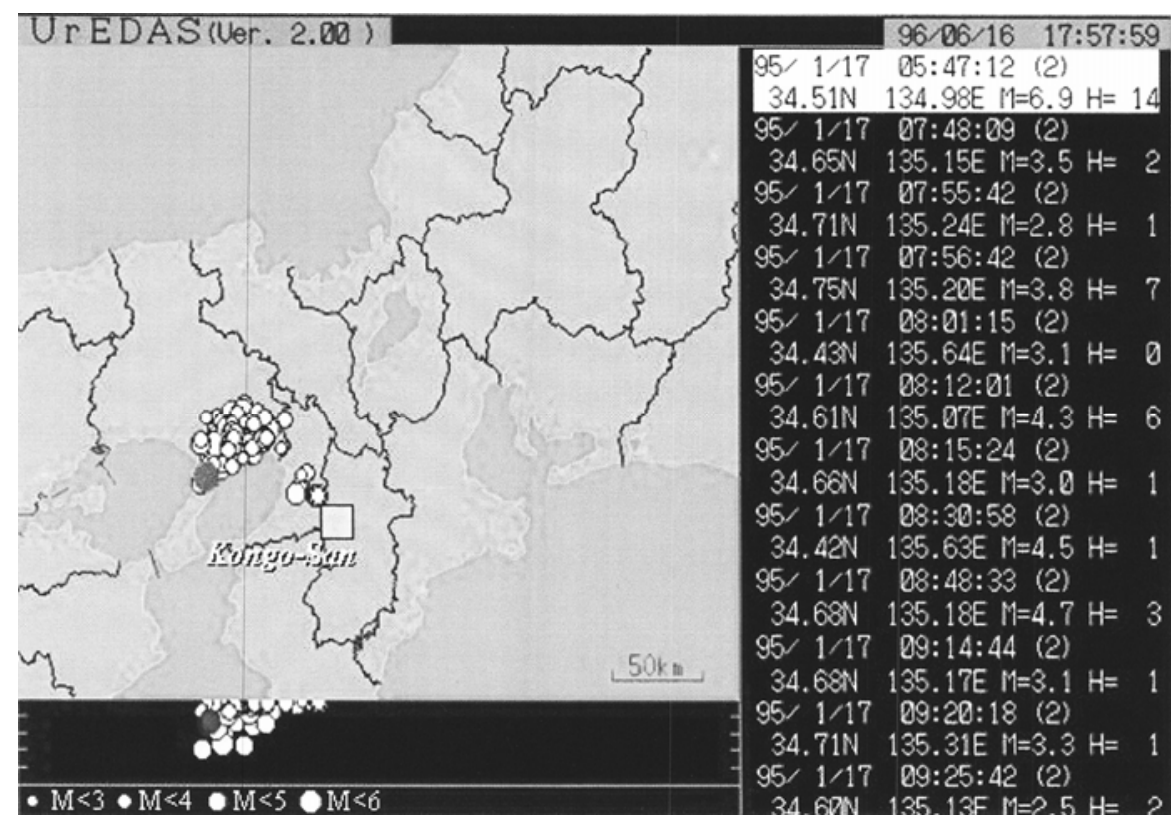

Fig. 13.20 The result of monitoring the 1995 Kobe earthquake.

\section{(3) The 2003 Miyagiken-Oki earthquake}

At the time of the Miyagiken-Oki Earthquake, Kitagami plain, situated in the northern part of Honshu Island, was hit by large earthquake motion and damage was caused. The Tohoku Shinkansen line runs along the eastern edge of this plain and suffered damage to the columns of viaducts. The Coastline Compact UrEDAS for front detection issued a P-wave alarm for the damaged section three seconds after P-wave detection, and the alarm reached there before the P-wave arrival at the section. The on-site Compact UrEDAS then issued the P-wave alarm one second after P-wave detection. After that, the on-site Compact UrEDAS re-issued the $40 \mathrm{Gal}$ alarm before $\mathrm{S}$-wave arrival.

Figure 13.21 is a schematic illustration showing the relationship between the wave propagation and the P-wave alarm. The times shown in Fig. 13.21 are based on the origin time. Observed acceleration along the Shinkansen line was high, ranging from $300 \mathrm{Gal}$ to $600 \mathrm{Gal}$.

At the time of this earthquake, there were trains stopping at stations or running at low speeds near the station at the early warning section. Only one train (Hayate \#26) was running at full speed on the new section outside the early warning section. Although Hayate \#26 failed to notice the earthquake due to the train's speed, around the train about $300 \mathrm{Gal}$ was observed on the ground. 

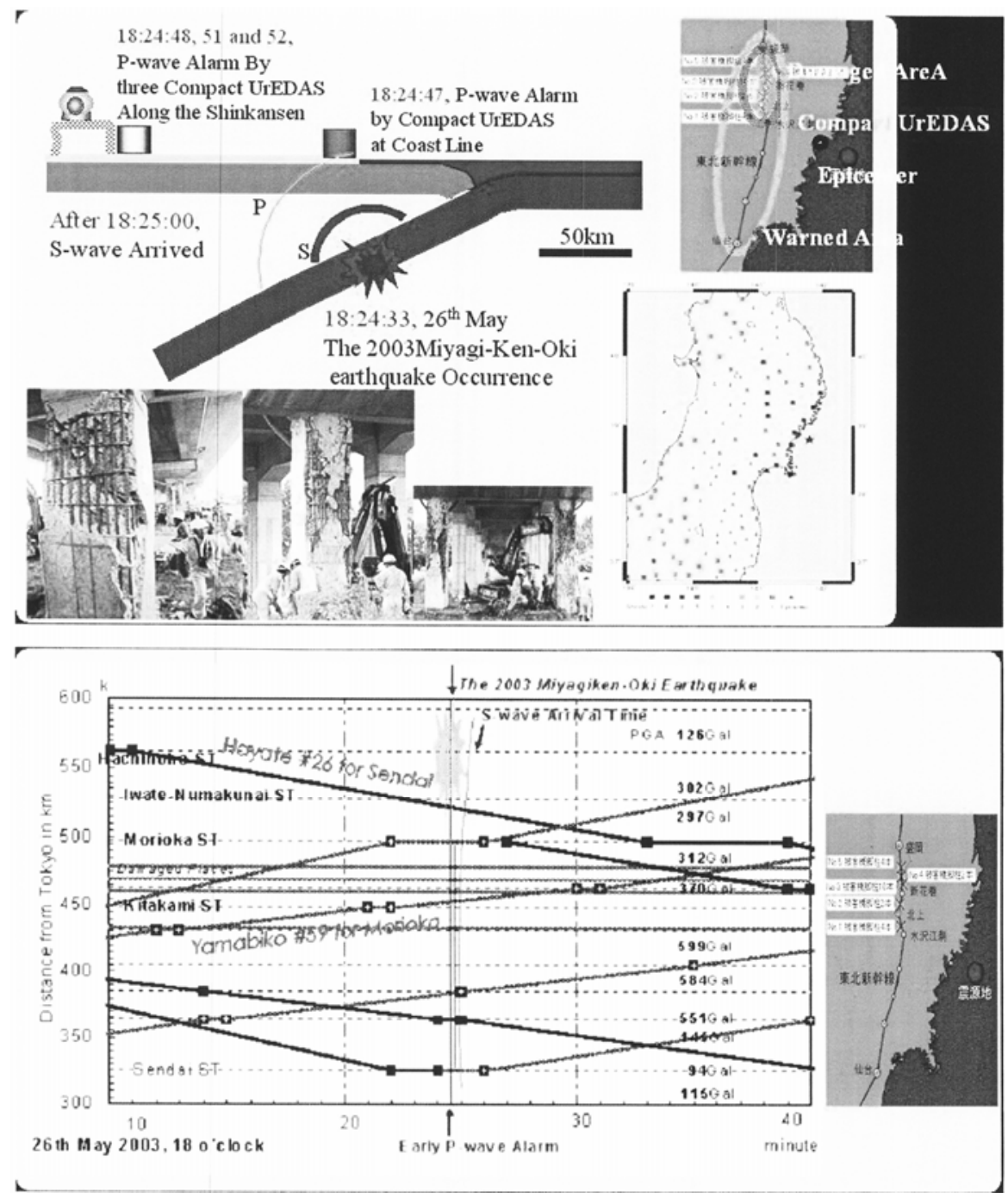

Fig. 13.21 Train operation at the time of the 2003 Miyagiken-Oki earthquake.

On this occasion, there was no train near the damaged area. If the earthquake had occurred a few minutes after or before, the train might have derailed as it was traveling along the section displaced by earthquake damage. On this section, viaducts were actually damaged and it was just a fortunate nothing more than to lead the hazard because of no train. 
The first P-wave alarm was issued from the Coastline Compact UrEDAS, and P-wave alarms were then issued from three Compact UrEDAS along the Shinkansen line. This earthquake caused damage to the Shinkansen viaducts. The damaged area is located in the first warned area and the alarm was issued prior to the arrival of the destructive strong motion. Three Compact UrEDAS issued P-wave alarms located near the damaged area. The Compact UrEDAS showed very good performance as the typical merit of the early warning system during this earthquake.

\section{(4) The 2004 Niigataken Chuetsu earthquake}

At the time of the Niigataken Chuetsu Earthquake, there were four trains running in the focal area. There are four observatories called Oshikiri SP, Nagaoka SSP, Kawaguchi SS and Muikamachi SP, from north to south. Of these stations, Kawaguchi and Nagaoka issued both P-wave and S-wave alarms, and the others issued only an S-wave alarm. Every station issued an alarm for the section to the next station (see Fig. 13.22). At first Kawaguchi and then Nagaoka issued the P-wave alarm. Subsequently, Oshikiri and Muikamachi issued a $40 \mathrm{Gal}$ alarm. As a result, trains Toki \#325 and \#332 received the alarm 3.6 seconds after the earthquake, Toki \#406 4.5 seconds after and Toki \#361 11.2 seconds. The section damaged was between Muikamachi and Nagaoka. Trains traveling on this section received the alarm immediately, proving that the alarm system settings were appropriate.

The UD component of earthquake motion predominate the high frequency more than $10 \mathrm{~Hz}$. The Shinkansen line runs from north to south and the EW component seems to effect derailment. In the case of the EW component, there is a peak at $1.5 \mathrm{~Hz}$ and the range of 1 to $2.5 \mathrm{~Hz}$ predominates. The natural frequency of the Shinkansen vehicle is included this frequency range.

The Kawaguchi observatory detected the $\mathrm{P}$ wave 2.9 seconds after the earthquake occurred, and one second after that, or 3.9 seconds after the event, issued a P-wave alarm. When the derailed train, Toki \#325, encountered the earthquake motion when traveling at $75 \mathrm{~m}$ from the Takitani tunnel end, it was three seconds after earthquake occurrence. 3.9 seconds after the earthquake, the train received the alarm from the Compact UrEDAS and the power supply was interrupted. The Shinkansen train situated automatically to apply the break immediately at the interruption of power supply. The driver put on the emergency brake after recognizing the Compact UrEDAS alarm. The S-wave hit the train 2.5 seconds after the alarm and more one second later a large shock hit the train, which continued for about five seconds. Figure 13.23 shows the schematic diagram for this earthquake. 


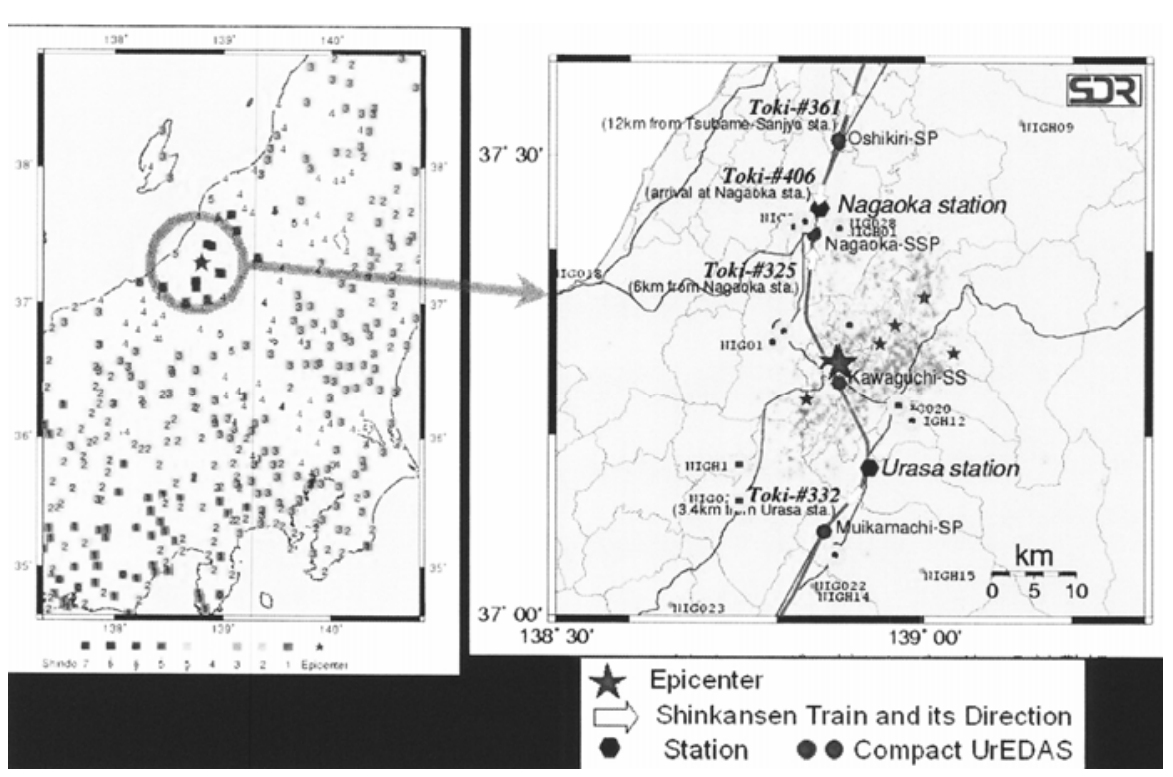

Fig. 13.22 Overview of the 2004 Niigataken Chuetsu earthquake.

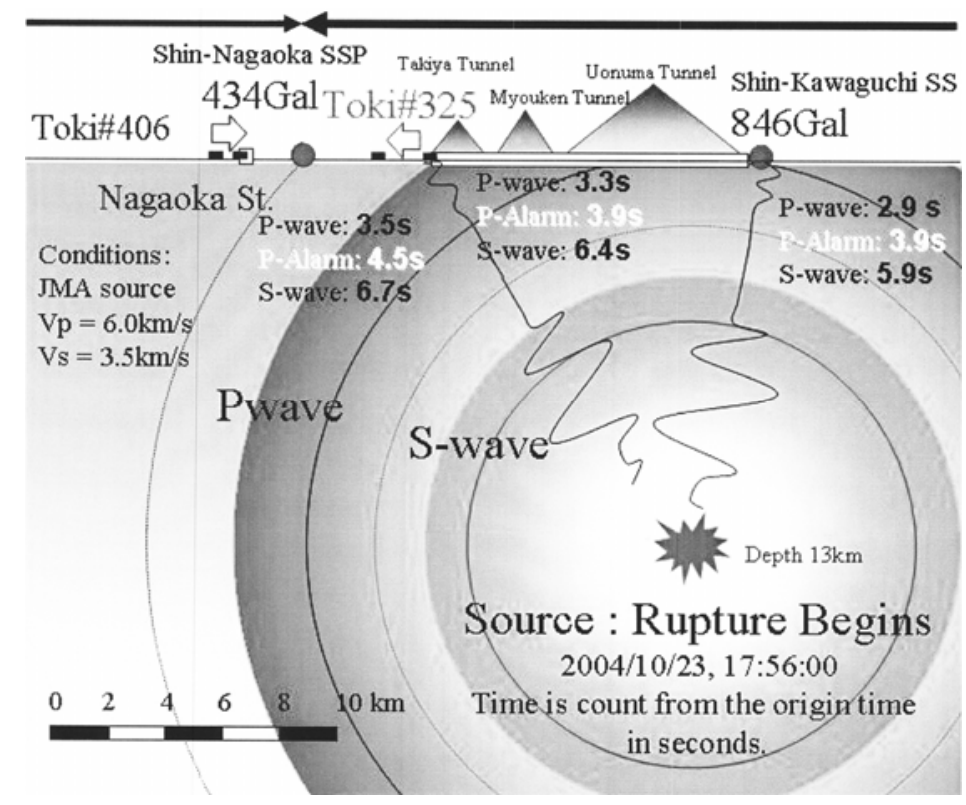

Fig. 13.23 Schematic diagram of the 2004 Niigataken Chuetsu earthquake. 
As the result of simulation using the strong-motion records at Kawaguchi and Nagaoka, real-time intensity (RI) rose sharply with the earthquake motion arrival and immediately reached the P-wave alarm level. This RI is a real-time value and the maximum value fits the instrumental intensity of JMA. Because FREQL, the new generation of Compact UrEDAS, improves the reliability of P-wave distinction, FREQL can issue the alarm immediately after the P-wave alarm threshold is exceeded. If FREQL had been installed instead of Compact UrEDAS, both Kawaguchi and Nagaoka observatory would issued the P-wave alarm 0.2 and 0.6 seconds after Pwave detection, respectively. Table 13.3 summarizes the simulation results. In this case, the P-wave alarm reached the derailed section before Pwave arrival. Accordingly, FREQL minimizes the process time for alarm.

Table 13.3 The result of the simulation for Niigataken Chuetsu Earthquake.

\begin{tabular}{lccc}
\hline Alarm and Accident Site & Kawaguchi & $\begin{array}{c}\text { Tunnel } \\
\text { Exit }\end{array}$ & Nagaoka \\
\hline 5HzPGA(Gal) & 864 & & 434 \\
RImax(MMI) & $6.6(10.9)$ & & $5.8(9.6)$ \\
Origin Time & $17: 56: 00$ & $17: 56: 00$ & $17: 56: 00$ \\
Recorded Detection Time & 03 & & 04 \\
Estimated P wave Arrival & 2.9 & 3.3 & 3.5 \\
Time & & & \\
Time of RI>2 & 3.1 & & 4.1 \\
P wave Alarm Time & 3.9 & 3.9 & 4.5 \\
Time of Acc $>10$ Gal & 3.4 & & 4.7 \\
Time of Acc $>40 G a l$ & 4.2 & & 5.9 \\
Time of Max 5Hz PGA & 7.7 & & 9.4 \\
Time of Max RI & 8.1 & & 9.5 \\
\hline
\end{tabular}

Figure 13.24 shows the details of the derailment. The derailed train, Toki \#325, consisted of 10 cars, from car 10 to car 1 along the traveling direction. The number of derailed axles is 22 out of a total of 40 axles. The last car, \#1, fell down the drain besides the track and tilted by about 30 degrees. The open circle indicates the location of broken window glass. The quantity of broken grass appears greater on the left due to the something bounce from the sound barrier, and tends to break one or two cars after the derailed car. The amount of broken glass from car 1 is exceeded by that of car \#2.

If it is assumed that the glass broken of car \#2 was caused by the derailment of cars \#4 and \#3, the paucity of broken glasses from car \#1 suggests that car \#2 did not derail during the earthquake motion. It is estimated that the frictional heat between the vehicle and the rails caused 
elongation and large displacement at the joints, and car \#1 derailed, making car \#2 derail.
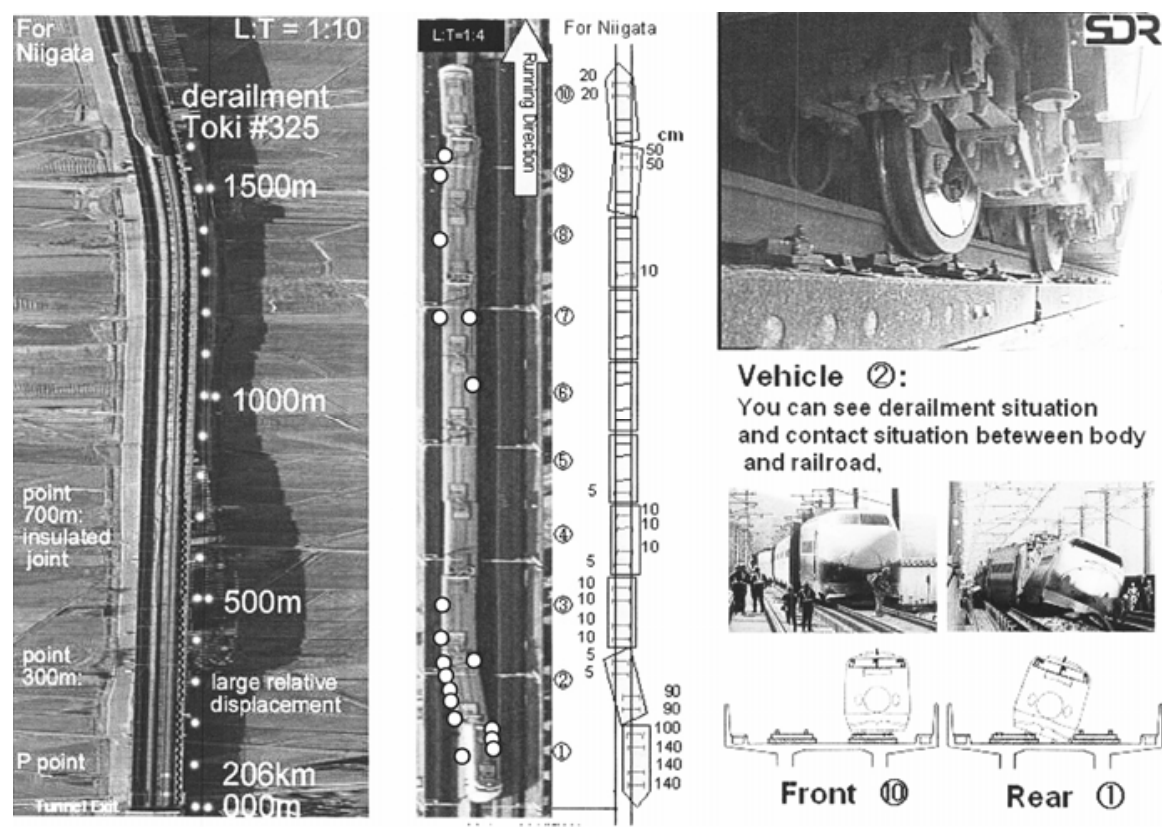

\section{Vehicle (2):}

You can see derailment situation and contact situation beteween body and railroad.

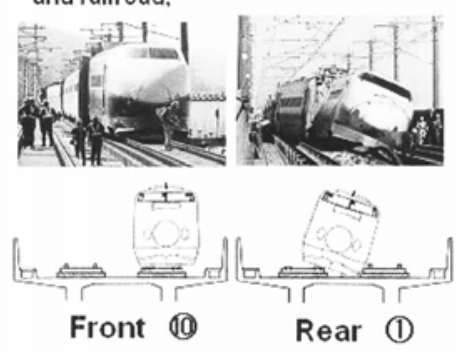

Fig. 13.24 Detailed situation of the derailment.

Deformation performance of viaducts is specified within one $\mathrm{cm}$ from the seismic design code. Although the designed natural frequency corresponding to the deformation performance is $2.5 \mathrm{~Hz}$, in practice it is $3.5 \mathrm{~Hz}$. The viaduct may thus be considered to behave statically against the earthquake motion less than around $1.5 \mathrm{~Hz}$. Figure 13.25 shows the relative deformation derived from the dimension of the viaduct columns. The heavy line shows the averaged deformation for each viaduct block, and it is estimated that the relative large occurred at the area farther from the tunnel exit. Taking into account the timing of earthquake occurrence, this is the point of derailment. 

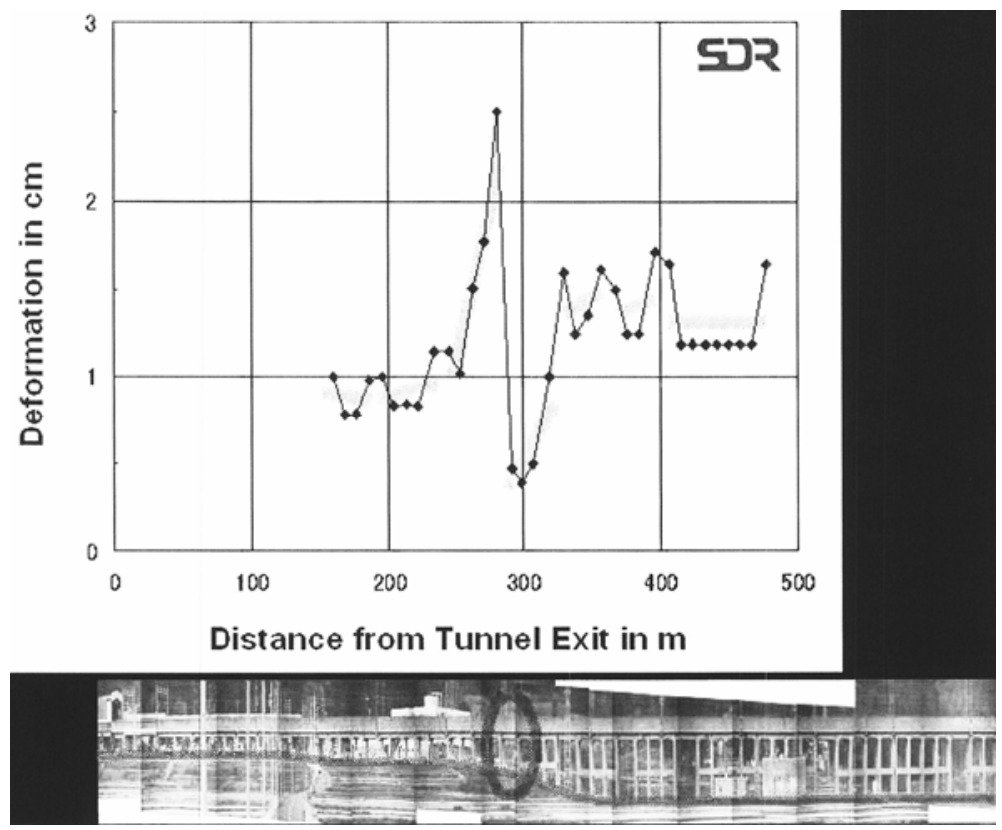

Fig. 13.25 Performance of the deformation (photo is mirror image).

Figure 13.26 outlines the circumstances of the derailment. It seems that the derailed cars were on the large displacement section by chance. The later the alarm reached, the more the number of derailed car, because of the risk of running the large displacement section. As a result, if the friction heat release value were higher, the derailment situation were more severe. On the other hand, the early warning slows the train down, which means that the main shock hits the train before the large displacement section and decreases while the train travels the section. The number of the derailed cars is thus expected to decrease and the derailment damage must be minor. In this regard, the P-wave alarm of the Compact UrEDAS demonstrates its effectiveness at making the derailment non-catastrophic. 


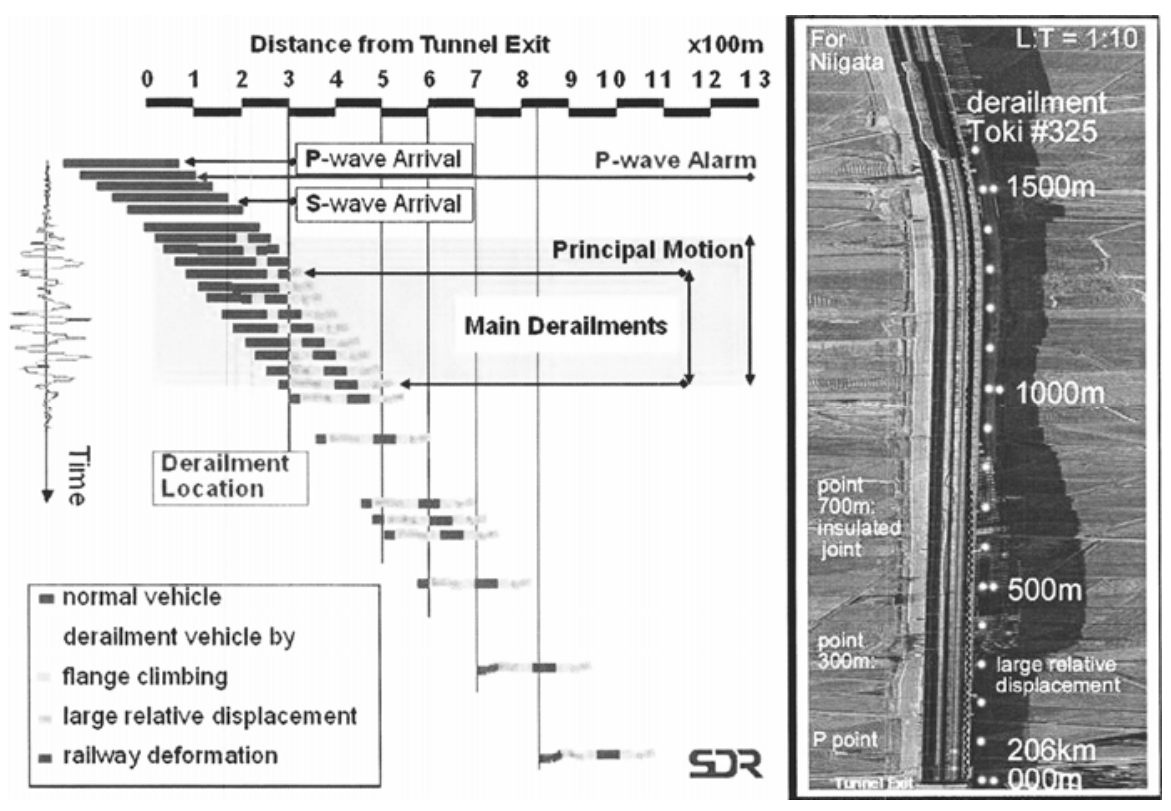

Fig. 13.26 Outline of the situation of the derailment.

\subsubsection{Research UrEDAS Worldwide}

Other than UrEDAS in practical use, more than five sets of UrEDAS have been installed for our research on high accuracy and shortening estimation times. Figure 13.27 shows the distribution map of the systems. Currently, Istanbul and Mexico City UrEDAS have been stopped but both the Caltech and UC Berkeley systems are working, and send an e-mail on the details of the detected earthquake.

Caltech Pasadena and Berkeley UrEDAS started observations in July 2000 and February 2001, respectively. These observations are supported by Caltech and UC Berkeley, respectively. After earthquake detection, these UrEDAS sends an e-mail in real time. A formaer type of Pasadena UrEDAS was at work from September 1993 to August 1999, and observed the 1994 Northridge Earthquake.

The Berkeley UrEDAS is located just above the Hayward fault while the Pasadena UrEDAS is surrounded by faults, like Fig. 13.28. Despite the influence of faults, the Pasadena UrEDAS shows higher-accuracy estimation of focal parameters than Berkeley UrEDAS, and performance of earthquake detection is effective at both stations. 


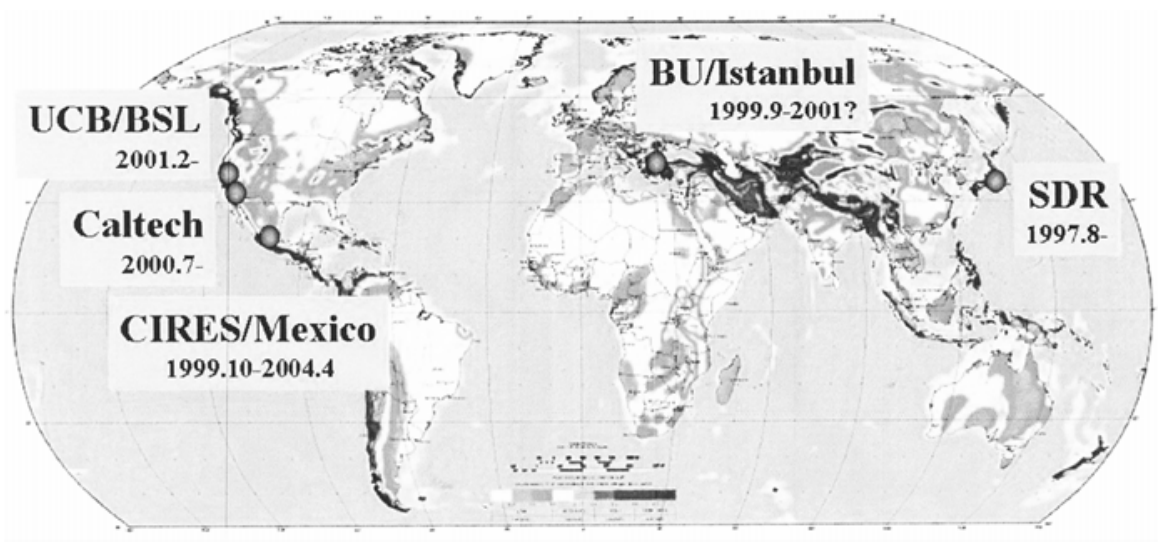

Fig. 13.27 Research UrEDAS in the world.
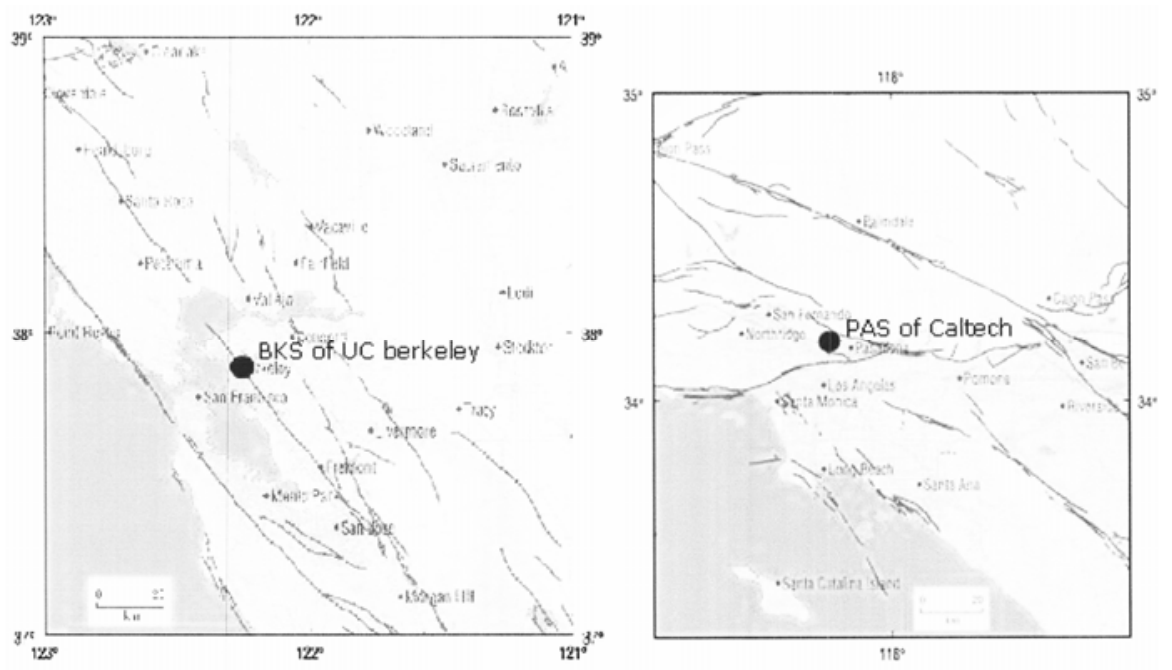

Fig. 13.28 Location of Pasadena and Berkeley UrEDAS.

\subsection{Challenges for Earlier Estimation with High Accuracy}

Figure 13.29 shows comparisons between UrEDAS real-time estimation results and USGS results. The three figures on the left are the results estimated by using three seconds of initial motion; the right-hand side shows 
the results of estimation by using one-second data of initial motion. From these figures, the accuracies of three-second estimations are not so good for the epicentral azimuth, within 0.5 for magnitude, half to twice as great for hypocentral distance, albeit excluding earthquakes over several hundreds km away. Contrasting with this, the accuracies of one-second estimations are within 30 degrees for epicentral azimuth, within 0.5 for magnitude, and half to twice as great for hypocentral distance, including distant earthquakes over $1000 \mathrm{~km}$. These results are interesting.

\subsection{Conclusion}

It is necessary that the measuring and processing functions of an earthquake disaster prevention information system be constructed in fully automated fashion and operated automatically.

The alarm in the expected damage area is of prime importance. The independent on-site warning system should be constructed with the awareness that network information from the source region is useful if it comes. Sometimes a robust, inexpensive and reliable system for disaster prevention should be built for early warning and indicating dangerousness even if rack of some accuracy. Efforts have been made to develop and disseminate small, low-cost on-site earthquake alarm instrumentation as a supporting tool for independent disaster prevention. It is expected to distribute many of this kind of equipments cooperating with existing information systems to reduce damage by disaster.

The necessary qualities for early warning systems may be summarized as follows:

- Fully Automated: As the time margin is limited, the facility should be directly controlled without human judgment.

- Quick and Reliable: As there is limited time to respond to earthquake motion, this kind of system is required to be quick and reliable.

- Small and Cheap: To install easily, the system must be small and cheap.

- Independence: To issue fail-safe alarms, the system must be independent of other systems.

- Easy to Connect Network: To deliver the earthquake information, the system must be easy to connect network.

- Accuracy is Better: For the alarm, accuracy of the information is not such a serious problem. 

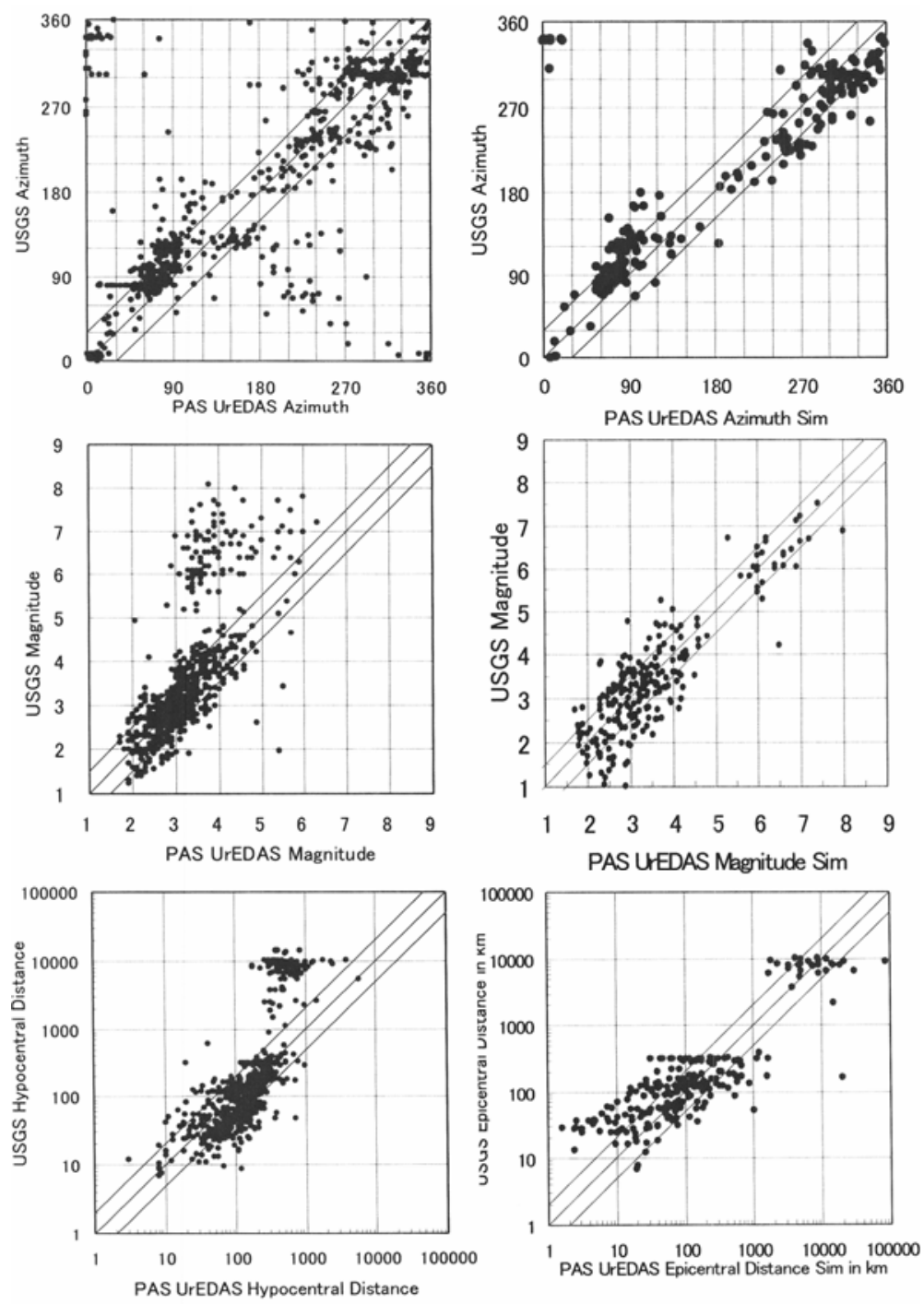

Fig. 13.29 UrEDAS simulation for next generation.

\subsection{Acknowledgment}

The authors would like to sincerely express their utmost appreciation and gratitude to the following people for their friendly cooperation and great contribution to setting up UrEDAS in each place, checking the condition of such systems, and fruitful discussion of the results observed. 
- Prof. Hiroo Kanamori, California Technical Institute

- Prof. Fumiko Tajima, Hiroshima University

- Dr. Robert A. Uhrhammer, University of California, Berkeley Seismological Laboratory

- Prof. Mustafa Erdik, Kandilli Observatory and Earthquake Research Institute, Boğaziçi University

- Mr. Juan Manuel Espinosa Aranda, Centro de Instrumentacion y Registro Sismico

- Mr. Samuel Maldonado Caballero, Centro de Instrumentacion y Registro Sismico

UrEDAS in practical use was realized by the following companies and organizations:

- Central Japan Railway Company, Co., Ltd.

- West Japan Railway Company, Co. Ltd.

- East Japan Railway Company, Co. Ltd.

- Wakayama prefecture

- Tokyo Metro Co. Ltd.

The authors thank the hyper rescue teams of Tokyo Fire Department who opened up the new field of the early warning system.

\section{References}

1. Nakamura Y (1996) Research and Development of Intelligent Earthquake Disaster Prevention System UrEDAS and HERAS. Journal of Structural Mechanics and Earthquake Engineering, Japan Society of Civil Engineers 531(I34):1-33

2. Nakamura Y (1988) On the Urgent Earthquake Detection and Alarm System (UrEDAS). $9^{\text {th }}$ World Conference on Earthquake Engineering, Vol. VII, pp 673-678, August 2-9, 1988

3. The Chugoku Shimbun (2001) "Is Shinkansen Safe?" and "No clincher to countermeasure for derailment", reported on 1st and 2nd May, News Special 2001, May 2001

4. Proceedings of the Study Meeting for damage of recent earthquakes, the Miyagiken-Oki and the Algeria earthquakes (2003) Japan Society of Civil Engineers, 21st August 2003 (in Japanese)

5. Nakamura Y (2004) UrEDAS, Urgent Earthquake Detection and Alarm System, now and future. $13^{\text {th }}$ World Conference on Earthquake Engineering, paper \#908, 2004

6. Nakamura Y (2004) On a Rational Strong Motion Index Compared with Other Various Indices. $13^{\text {th }}$ World Conference on Earthquake Engineering, paper \#910, 2004 


\section{Appendix}

San Francisco Daily Evening Bulletin of 3rd November 1868 Earthquake Indicator

EDITOR BULLETIN. Since the Japanese magnet indicator has proved a failure, we are now obliged to look for some other means of prognosticating these fearful convulsions, and I wish to suggest the following mode by which we may make electricity the means, perhaps, of saving thousands of lives in case of the occurrence of more severe shocks than we have yet experienced. It is well known that these shocks are produced by a wavemotion of the surface of the earth, the waves radiating from a center just as they do in water when a stone is thrown in. If this center happens to be far enough from this city, we may be easily notified of the coming wave in time for all to escape from dangerous buildings before it reaches us. The rate of velocity, as observed and recorded in Dr. J. B. Trask's work on Earthquakes in California from 1800 to 1864 , is 61.5 (six and one fifth) miles per minute, or a little less per hour (40 miles) than the tidal wave is reported to have traveled across the ocean to this port from the Sandwich Islands or Japan.

A very simple mechanical contrivance can be arranged at various points from 10 to 100 miles from San Francisco, by which a wave of the earth high enough to do damage, will start an electric current over the wires now radiating from this city, and almost instantaneously ring an alarm bell, which should be hung in a high tower near the center of the city. This bell should be very large, of peculiar sound, and known to everybody as the earthquake bell. Of course nothing but the distant undulation of the surface of the earth should ring it. This machinery would be self-acting, and not dependent on the telegraph operators, who might not always retain presence of mind enough to telegraph at the moment, or might sound the alarm too often. As some shocks appear to come from the west, a cable might be laid to the Farallone Islands, 25 miles distant, and warnings thus given of any danger from that direction.

Of course there might be shocks, the central force of which was too near this city to be thus protected, but that is not likely to occur once in a hundred times.

J.D. COOPER, M.D. 
